\title{
miR-505 inhibits cell growth and EMT by targeting MAP3K3 through the AKT-NFkB pathway in NSCLC cells
}

\author{
HUAPING TANG $^{1}$, WEIHONG LV ${ }^{2}$, WENXIN SUN ${ }^{1}$, QIAOJIE BI $^{3}$ and YUEQIN HAO ${ }^{1}$ \\ Departments of ${ }^{1}$ Respiration, ${ }^{2}$ Medical and ${ }^{3}$ Emergency, Qingdao Municipal Hospital, Qingdao, Shandong 266071, P.R. China
}

Received May 22, 2018; Accepted December 10, 2018

DOI: 10.3892/ijmm.2018.4041

\begin{abstract}
MicroRNAs (miRNAs) are short non-coding RNAs, which generally regulate gene expression at the post-transcriptional level. Dysregulation of miRNAs has been reported in numerous cancer types, including lung cancer. In the present study, the role of miR-505 in non-small cell lung cancer (NSCLC) cells was investigated. miR-505 served a tumor suppressor role in NSCLC cells. By reverse transcriptase-quantitative polymerase chain reaction detection, it was demonstrated that miR-505 was downregulated in NSCLC tissues and cell lines, which is negatively associated with large tumor size, Tumor-Node-Metastasis stage and distant metastasis in patients with NSCLC. Functional studies revealed that miR-505 inhibited cell proliferation, migration, invasion and epithelial-mesenchymal transition progress in vitro and tumor growth in vivo. Mechanically, mitogen-activated protein kinase kinase kinase 3 (MAP3K3) was identified as a direct target of miR-505 by binding to its 3'untranslated region and demonstrated to mediate the tumor suppressor roles of miR-505 in NSCLC cells. The effect of miR-505 on the activation of $\mathrm{AKT} /$ nuclear factor- $\mathrm{B}$ ( $\mathrm{NF} \kappa \mathrm{B})$ pathway, which was downstream targets of MAP3K3, was further analyzed by western blot analysis and immunofluorescence analyses. The data demonstrated the inhibition of the $A K T / N F \kappa B$ pathway upon overexpressing miR-505 and the activation of AKT/NFкB pathway upon silencing miR-505. Collectively, the data revealed the novel role and target of miR-505 in NSCLC cells, which may provide novel insights regarding its role in the carcinogenesis of NSCLC and its potential values for clinical applications.
\end{abstract}

Correspondence to: Dr Yueqin Hao, Department of Respiration, Qingdao Municipal Hospital, 5 Donghai Road, Qingdao, Shandong 266071, P.R. China

E-mail: 15726259705@163.com

Key words: microRNA-505, proliferation, epithelial-mesenchymal transition, mitogen-activated protein kinase kinase kinase 3 , non-small cell lung cancer, AKT/nuclear factor- $\kappa \mathrm{B}$

\section{Introduction}

Lung cancer is the second most common cancer, which also accounts for the most common cause of cancer-associated mortalities in males and the second most common cause in females. Approximately $14 \%$ of new cancer cases were lung cancer from 2005-2014 in USA (1). There are two main types of lung cancer, small-cell lung cancer (SCLC) and non-SCLC (NSCLC), and 80-85\% lung cancer cases were classified as NSCLC globally in 2008, which include a number of subtypes, including adenocarcinoma ( 40\%), squamous cell carcinoma (25-30\%), undifferentiated carcinoma or large cell carcinoma (10-15\%) and a few other subtypes, such as sarcomatoid carcinoma (2). Patients with NSCLC are frequently diagnosed at advanced stages of disease (1). The mean 5-year survival rate for patients with NSCLC in 2015 is only 18\% globally (1), due to its known heterogeneity, including the complex molecular and tumor microenvironmental factors, and the limited therapy options (2). Recently, studies regarding NSCLC therapeutics have been conducted, but the treatment methods remain limited due to the poor prognosis (3-6). Therefore, understanding the molecular mechanism responsible for the pathogenesis of NSCLC remains urgently required.

MicroRNAs (miRNAs) are a large group of small non-coding RNAs that generally negatively regulate gene expression at the post-transcriptional level by binding to the 3 'untranslated region (3'UTR) of the transcripts (7). They serve fundamental effects in the regulation of different intracellular processes, including cell proliferation, migration, invasion, metastasis, cell cycle and apoptosis (8-10). Numerous studies revealed that dysregulation of miRNAs is associated with the initiation and development of cancer, and miRNAs act as oncogenes or suppressor genes (11-15).

miR-505 is located in chromosome $\mathrm{X}$ of humans, and a number of studies reported its functional roles in different diseases, including osteosarcoma, cervical cancer and hepatoma cell cancer (16-19). For example Yang et al (17), demonstrated that the level of miR-505 in plasma was significantly elevated in hypertensive patients, and miR-505 overexpression impaired the migration and tube formation of endothelial cells by targeting fibroblast growth factor 18 . Escate et al (18), reported that miR-505 was significantly downregulated in monocyte-derived macrophages of patients with familiar hypercholesterolemia (FH), and regulated the chemokine receptor $\mathrm{C}-\mathrm{C}$ motif chemokine receptor 3 (CCR3), 
CCR4 and C-X-C motif chemokine receptor 1 expression via the transcription factor runt related transcription factor 1 , indicating that miR-505 is involved in the chronic inflammatory condition in FH innate immunity cells. In human osteosarcoma (19) and hepatomacarcinoma (20), miR-505 was downregulated in cancer specimens and cell lines. Functional experiments revealed that miR-505 suppressed proliferation and invasion by directly targeting high mobility group box 1 (20). Similarly, miR-505 acts as a tumor inhibitor in cervical cancer (21) and endometrial cancer (22) by directly targeting frizzled class receptor 4 and transforming growth factor- $\alpha$, respectively. However, there is limited knowledge regarding the molecular function and mechanism of miR-505 in NSCLC.

In the present study, it was demonstrated that miR-505 was downregulated in NSCLC tissues and cell lines, compared with their paired normal groups and the normal lung epithelial cells, respectively. Functionally, it was indicated that miR-505 inhibited cell proliferation, tumor growth and epithelial-mesenchymal transition (EMT) processes in NSCLC cells. Mechanically, mitogen-activated protein kinase kinase kinase 3 (MAP3K3) was identified as a direct target of miR-505 and it was demonstrated to mediate the suppressor role of miR-505 by inhibiting AKT/nuclear factor- $\kappa \mathrm{B}(\mathrm{NF} \kappa \mathrm{B})$ activation in NSCLC cells. The data provide a novel insight into the pathogenesis of NSCLC and the associated molecules may serve as novel biomarkers for the diagnosis or therapeutic applications for NSCLC in the future.

\section{Materials and methods}

Clinical specimen and cell lines. A total of 21 pairs of human NSCLC tissues were obtained from the surgical resection of patients with NSCLC in Qingdao Municipal Hospital (Qingdao, China) from December 2017 to February 2018. Written informed consent was obtained from all enrolled patients, and all relevant investigations were performed according to the principles of the Declaration of Helsinki. All samples were confirmed through the Department of Pathology in Qingdao Municipal Hospital. The clinical specimens used in the present study were pathologically based on the eighth edition of the Tumor-Node-Metastasis Staging Classification for Urologic Cancers (23). Pathologists from the Qiagdao Municipal Hospital who were blind to the study confirmed the pathology of the specimens. All tissue samples were frozen in liquid nitrogen immediately following resection and stored at $-80^{\circ} \mathrm{C}$ until further use. Ethical approval for the study was obtained from the Ethics Committee of Qingdao Municipal Hospital (approval no. QMH20170233). The human lung cancer cell lines A549, H1066, H460, H522 and SPC-A1, and the human normal lung epithelial cell BEAS-2B were purchased from ATCC (American Type Culture Collection, Manassas, VA, USA), and cultured in RPMI-1640 or Dulbecco's modified Eagle's medium (Invitrogen; Thermo Fisher Scientific, Inc., Waltham, MA, USA), supplemented with $10 \%$ fetal bovine serum (FBS; Hyclone; GE Healthcare Life Sciences, Logan, UT, USA) and $1 \%$ penicillin-streptomycin. Cell transfection was performed by Lipofectamine ${ }^{\circledR} 2000$ (Invitrogen; Thermo Fisher Scientific, Inc.), according to the manufacturer's protocols. A549 cells or H460 cells $\left(4 \times 10^{5}\right)$ were planted in 6-well plates overnight at $37^{\circ} \mathrm{C}$ to ensure that cell confluence could reach $60-80 \%$ at the time of transfection. Following $6 \mathrm{~h}$ transfection at $37^{\circ} \mathrm{C}$, the serum-free Opti-MEM medium (Gibco; Thermo Fisher Scientific, Inc.) was replaced with Dulbecco's modified Eagle's medium containing $10 \%$ FBS. They were transiently transfected with $3 \mu \mathrm{g}$ pri-miR-505 or pcDNA3 and $20 \mu \mathrm{mol}$ antisense oligonucleotide (ASO)-miR-505 or ASO-negative control (NC) in a well of 6 -well plate. The sequences were as follows: pri-miR-505-sense, 5'-CGCGGATCCCAGACTCCCAGCA ATCAC-3', pri-miR-505-antisense, 5'-CCGGAATTCGCAGT ATTCCCACCATTT-3'; ASO-miR-505, 5'-AGGAAACCAG CAAGUGUUGACG-3', ASO-NC, 5'-UCAUCGUAUCAGC UAUAUCGCA-3' (Guangzhou RiboBio Co., Ltd., Guangzhou, China). Cells were collected for reverse transcription-quantitative PCR (RT-qPCR), proliferation, migration, invasion, apoptosis and cell cycle assay analyses at $24 \mathrm{~h}$. At $48 \mathrm{~h}$ post-transfection, cells were collected for western blot analysis, immunofluorescence staining and the enhanced green fluorescent protein fluorescent reporter assay.

$R N A$ extraction and $(R T-q P C R)$. Total RNA was extracted from A549, H1066, H460, H522, SPC-A1 and BEAS-2B cells and frozen NSCLC tissues using TRIzol ${ }^{\circledR}$ reagent (Thermo Fisher Scientific, Inc.), according to the manufacturer's protocols. Reverse transcription was then performed. Gene-specific primers were used to synthesize miR-505 or MAP3K3 cDNA from total RNA. U6 small nuclear RNA (snRNA) and $\beta$-actin were used as internal controls for miR-505 and MAP3K3 detection, respectively. The expression levels were determined by qPCR with a SYBR-Green PCR Master Mix kit (Invitrogen; Thermo Fisher Scientific, Inc.), according to the manufacturer's protocols. The qPCR conditions were as follows: $95^{\circ} \mathrm{C}$ pre-denaturation for $5 \mathrm{~min}$, followed by 33 cycles of denaturation at $94^{\circ} \mathrm{C}$ for $30 \mathrm{sec}$, annealing and synthesis at $58^{\circ} \mathrm{C}$ for $30 \mathrm{sec}$ and $70^{\circ} \mathrm{C}$ for $30 \mathrm{sec}$, and a final extension step at $72^{\circ} \mathrm{C}$ for 5 min, using an Applied Biosystems Prism 7900HT Fast Real-Time PCR system (Applied Biosystems; Thermo Fisher Scientific, Inc.). The primer sequences were listed in Table I. The relative levels of mature miR-505 and MAP3K3 mRNA were calculated by the $2{ }^{-\Delta \Delta} \mathrm{Cq}$ method (24) and normalized to U6 snRNA or $\beta$-actin mRNA levels, respectively.

Proliferation assays. The cell proliferation was measured in A549 and H460 cells using a Cell Counting Kit-8 (CCK-8; Sigma-Aldrich; Merck KGaA, Darmstadt, Germany). A total of $5 \times 10^{3}$ cells/well of A549 and H460 cells were transfected with $0.3 \mu \mathrm{g}$ pri-miR-505 (overexpression), $20 \mathrm{nM}$ ASO-miR-505 (knockdown) or different combinations (pcDNA3+MAP3K3 or pri-miR-505+MAP3K3) of $0.3 \mu \mathrm{g}$ MAP3K3 overexpression vectors (Vigene Biosciences Inc., Rockville, MD, USA), and their respective controls were plated in 96-well plates at a proportionate density $\left(5 \times 10^{3}\right.$ cells/well for all groups) using Lipofectamine ${ }^{\circledR} 2000$ (Invitrogen; Thermo Fisher Scientific, Inc.), according to the manufacturer's protocols and incubated at $37^{\circ} \mathrm{C}$. Subsequently, cell viability at 24,48 and $72 \mathrm{~h}$ post-transfection was determined with a CCK-8 assay. Briefly, $10 \mu \mathrm{l}$ CCK-8 was added to each well and the plates were incubated for $4 \mathrm{~h}$ at $37^{\circ} \mathrm{C}$. The optical density (OD) at a wave length of $450 \mathrm{~nm}$ was determined using a microplate 
Table I. Primers for the present study.

RT-qPCR primers

Primer sequence (5'-3')

miR-505-RT

miR-505-qPCR-forward

Oligo-dT

U6-RT

U6-forward

miRNA-universal reverse

MAP3K3-qPCR-forward

MAP3K3-qPCR-reverse

$\beta$-actin-qPCR-forward

$\beta$-actin-qPCR-reverse

\author{
GTCGTATCCAGTGCAGGGTCCGAGGTGCACTGGATACGACAGGAAAC \\ TGCGGCGTCAACACTTGCT \\ TTTTTTTTTTTTTTTTTT \\ GTCGTATCCAGTGCAGGGTCCGAGGTATTCGCACTGGATACGACAAAATATGGAAC \\ TGCGGGTGCTCGCTTCGGCAGC \\ CCAGTGCAGGGTCCGAGGT \\ CAGCGGCGAGGGCTATGGAA \\ CAGCCTTGCCTGGGAGAA \\ CGTGACATTAAGGAGAAGCTG \\ CTAGAAGCATTTGCGGTGGAC
}

RT-qPCR, reverse transcription-quantitative polymerase chain reaction; miR, microRNA; MAP3K3; mitogen-activated protein kinase kinase kinase 3.

reader (Hitachi, Ltd., Tokyo, Japan). The OD values reflect the relative number of viable cells.

Colony formation assay. The differently-treated A549 and H460 cells (500 cell/well) were seeded into 12-well plates and cultured in Dulbecco's modified Eagle's medium containing $10 \% \mathrm{FBS}$ for 2 weeks at $37^{\circ} \mathrm{C}$ for colony formation. The culture medium was changed every 3 days. The colonies were then fixed in $100 \%$ methanol for $30 \mathrm{~min}$ at room temperature, stained with crystal violet for $30 \mathrm{~min}$ at room temperature and the numbers of macroscopically observable colonies were recorded.

Cell cycle analysis by flow cytometry. At post-transfection $48 \mathrm{~h}$, the A549 and H460 cells were trypsinized. Following washing by PBS three times, $1 \times 10^{6}$ cells were fixed in $100 \%$ thanol for $10 \mathrm{~min}$ at room temperature and incubated with $50 \mu \mathrm{g} / \mathrm{ml}$ Propidium Iodide (Cell Cycle Staining kit; Nanjing KeyGen Biotech Co., Ltd., Nanjing, China) for $10 \mathrm{~min}$ at room temperature in the dark and analyzed within 20 min using BD FACS Calibur (BD Biosciences, Franklin Lakes, NJ, USA). Flow cytometry was used to detect cell apoptosis and analyzed using FlowJo v.7.6.1 (FlowJo, LLC, Ashland, OR, USA).

Transwell migration and invasion assays. The migration and invasion were determined by Transwell assays individually. Briefly, 6x10 4 cells A549 and H460 cells were seeded into $8 \mu \mathrm{m}$ cell culture inserts (BD Biosciences), according to the manufacturer's protocols and placed in 24-well cell culture plates. Additionally, the upper chamber was coated with $100 \mu 1$ diluted Matrigel (2 mg/ml; Sigma-Aldrich; Merck KGaA) for the invasion assay. The lower chamber was filled with $600 \mu \mathrm{l}$ 20\% FBS (Gibco; Thermo Fisher Scientific, Inc.) medium. A549 and H460 cells $\left(6 \times 10^{4}\right)$ in $200 \mu 1$ serum-free Dulbecco's modified Eagle's medium were gently loaded onto each filter insert (upper chamber) and then incubated at $37^{\circ} \mathrm{C}$ for $48 \mathrm{~h}$. The filter inserts were removed from the chambers, fixed with 95\% methanol (Sigma-Aldrich; Merck KGaA) for $10 \mathrm{~min}$ at room temperature and stained with Harris' hematoxylin (Sigma-Aldrich; Merck KGaA) for $20 \mathrm{~min}$ at room temperature. The samples were subsequently washed with purified water three times, dried and mounted onto slides. Cell migration and invasion were assessed using a Transwell system (Corning Incorporated, Corning, NY, USA). The number of migrated and invaded cells was counted under a microscope (at $\mathrm{x} 200)$.

Western blot analysis. Total A549 cell lysates from different experiments (migration and invasion assay, EGFP reporter, $\mathrm{NF} \kappa \mathrm{B}$ pathway and xenograft model assays) were obtained by lysing the cells in radio-immunoprecipitation assay (RIPA) buffer (Wanlei Co., Ltd., Shanghai, China). The nuclear protein extraction from cells was obtained with a CelLytic ${ }^{\mathrm{TM}}$ NuCLEAR $^{\mathrm{TM}}$ Extraction kit (Sigma-Aldrich; Merck KGaA), according to the manufacturer's protocols. For tissues protein extraction, the tissues were ground up with liquid nitrogen, and then RIPA buffer was added, followed by ice bath cracking for $20 \mathrm{~min}$ at $4^{\circ} \mathrm{C}$. Subsequently, the cells were centrifuged at $4^{\circ} \mathrm{C}$ at $10,000 \mathrm{x} \mathrm{g}$ for $15 \mathrm{~min}$. Protein concentrations were quantified using the bicinchoninic acid protein assay kit (Beyotime Institute of Biotechnology, Shanghai, China), according to the manufacturer's protocols. A total of $30 \mu \mathrm{g}$ protein was resolved by $10 \%$ SDS-PAGE and transferred to polyvinylidene fluoride membranes (EMD Millipore, Billerica, MA, USA). Following blocking with $5 \%$ non-fat milk for $2 \mathrm{~h}$ at room temperature, the membranes were incubated with primary antibodies overnight at $4^{\circ} \mathrm{C}$, followed by incubation with a horseradish peroxidase-conjugated goat-anti-rabbit (cat. no. 4414S; 1:2,000) or goat-anti-mouse secondary antibody (cat. no. 4410S, 1:3,000) (both from Cell Signaling Technology, Inc., Danvers, MA, USA) at room temperature for $1 \mathrm{~h}$. Membranes were stripped and then re-incubated with a primary antibody against GAPDH (for total lysate or cytoplasm fraction; cat. no. ab9485; 1:5,000; Abcam, Cambridge, UK) or centromere protein A (for nuclear fraction; cat. no. ab65678; 1:2,000; Abcam) for normalization aim at room temperature for $4 \mathrm{~h}$, according to a previous study (25). Specific bands were visualized using enhanced chemiluminescence detection (Thermo Fisher Scientific, Inc.). The signal intensity was determined with ImageJ software v.1.48 (National Institutes of Health, Bethesda, MD, USA). The antibodies used in this study were listed in Table II. 
Table II. Antibodies used in the present study.

\begin{tabular}{|c|c|c|c|}
\hline Name & Company & Cat. no. & Dilution \\
\hline E-cadherin & Wanlei Co., Ltd., Shanghai, China & WL01482 & $1: 2,000$ \\
\hline Vimentin & Wanlei Co., Ltd. & WL00742 & $1: 1,000$ \\
\hline GAPDH & Abcam, Cambridge, MA, USA & ab9485 & $1: 5,000$ \\
\hline $\mathrm{Bcl} 2$ & Abcam & ab196495 & $1: 3,000$ \\
\hline Caspase 3 & Wanlei Co., Ltd. & WL02117 & $1: 1,500$ \\
\hline PARP & Wanlei Co., Ltd. & WL01932 & $1: 1,500$ \\
\hline MAP3K3 & Abcam & ab154362 & $1: 2,000$ \\
\hline IKK $\alpha$ & Abcam & ab32041 & $1: 2,000$ \\
\hline $\mathrm{IKK} \beta$ & Abcam & ab32135 & $1: 3,000$ \\
\hline pAKT & Abcam & ab38449 & $1: 1,000$ \\
\hline $\mathrm{AKT}$ & Abcam & ab8805 & $1: 2,000$ \\
\hline $\mathrm{p} 50$ & Wanlei Co., Ltd. & WL01917 & $1: 500$ \\
\hline p65 & Wanlei Co., Ltd. & WL01980 & $1: 1,000$ \\
\hline CENPA & Abcam & ab45694 & $1: 1,500$ \\
\hline
\end{tabular}

MAP3K3; mitogen-activated protein kinase kinase kinase 3; IKK $\beta$, IкB kinase $\beta$; CENPA, centromere protein A; Bcl2, B-cell lymphoma 2; PARP, poly(ADP) ribose polymerase; pAKT, phosphorylated AKT.

Prediction of miRNA targets. The hypothetical target of miR-505 was predicted using miRDB (www.mirdb. org), microRNA.org (www.microrna.org) and TargetScan human 7.2 (www.targetscan.org), which revealed that the 3'UTR of MAP3K3 may be complementarily paired with the seed sequences of miR-505.

EGFP reporter assay. The MAP3K3 3'UTR was cloned into a pcDNA3/EGFP vector (Shanghai GeneChem Co., Ltd., Shanghai, China) and mutations were introduced at potential miR-505 binding sites. The constructed pcDNA3/EGFPMAP3K3-3'UTR $(0.5 \mu \mathrm{g})$ or its mutated form pcDNA3/EGFPMAP3K3-3'UTR-mut $(0.5 \mu \mathrm{g})$ were co-transfected with pri-miR-505 (0.5 $\mu \mathrm{g}$; pri-miR-505-sense, 5'-CGCGGATCCCA GACTCCCAGCAATCAC-3', pri-miR-505-antisense, 5'-CCG GAATTCGCAGTATTCCCACCATTT-3'), ASO-miR-505 (20 nM; ASO-miR-505, 5'-AGGAAACCAGCAAGUGUU GACG-3') or their respective control vector (pcDNA3; Vigene Biosciences Inc.) or oligos (ASO-NC, 5'-UCAUCGUAUCA GCUAUAUCGCA-3') into A549 and H460 cells, and pDsRed2-1 vector (Clontech Laboratories, Inc., Mountainview, CA, USA) also co-transfected for normalization aim in 48-well plates using Lipofectamine 2000 (DNA:Lipofectamine 2000, 1:1). At $48 \mathrm{~h}$ post-transfection, the total proteins were extracted by RIPA buffer and the fluorescence intensities of GFP and red fluorescent protein (RFP) were measured. The EGFP activity was measured using a spectrophotometer (cat. no. F4500; Hitachi, Ltd.) at $528 \mathrm{~nm}$. RFP-expressing plasmid was integrated as a transfection efficiency control.

Immunofluorescence staining. $4 \times 10^{4}$ A549 cells transfected with specific plasmids (1 $\mu \mathrm{g}$ pcDNA3, $1 \mu \mathrm{g}$ pri-miR-505, $1 \mu \mathrm{g}$ MAP3K3 or $0.5 \mu \mathrm{g}$ pri-miR-505+0.5 $\mu \mathrm{g}$ MAP3K3) using Lipofectamine ${ }^{\circledR} 2000$, according to the manufacturer's protocols were seeded with Dulbecco's modified Eagle's medium containing $10 \%$ FBS in 24-well plates for $48 \mathrm{~h}$ and then for immunofluorescence staining. The cells were washed in PBS three times and fixed with $4 \%$ paraformaldehyde for $30 \mathrm{~min}$ at room temperature. Following cells being washed with PBS three times, the cells were permeabilized using $0.1 \%$ Triton-X-100 for $10 \mathrm{~min}$ at room temperature and blocked in 10\% donkey serum (Beyotime Institute of Biotechnology) for $30 \mathrm{~min}$ at room temperature. The cells were subsequently incubated with primary antibodies against p50 (cat. no. WL01917, 1:50) and p65 (cat. no. WL01980; 1:50) (both from Wanlei Co., Ltd.) overnight at $4^{\circ} \mathrm{C}$. The following day, cells were washed in PBS three times and then incubated at room temperature for $1 \mathrm{~h}$ with a goat anti-rabbit IgG H\&L Alexa Fluor ${ }^{\circledR} 488$ (cat. no. ab150077; 1:100; Abcam), followed by incubation with DAPI (1:1,000; Sigma-Aldrich; Merck $\mathrm{KGaA})$ at room temperature. Images were captured under a confocal microscope (at x1,000).

In vivo xenograft model. Animal protocols were approved by Qingdao Municipal Hospital Animal Care and Use Committee (approval no. QMH20170331A; Qingdao, China). The methods were conducted in accordance with the approved guidelines. For the in vivo study, 6-week-old female BALB/c athymic nude mice (Institute of Zoology, Chinese Academy of Sciences, Shanghai, China) were used [ $\mathrm{n}=8$; divided into 2 groups; weight, 20-30 g; maintenance conditions: Temperature, $18-29^{\circ} \mathrm{C}$; relative humidity, 50-60\%; free access to clean food and water; and lighting for $10 \mathrm{~h}$ (lights turned on at 8:00 every day and turned off at 18:00)]. A total number of $1 \times 10^{7}$ stably transfected (Lenti-control or Lenti-miR-505) A549 cells were implanted subcutaneously into the armpit of nude mice. For stable transfections, A549 cells were plated in a 6-well plate $\left(3 \times 10^{4}\right.$ cells $\left./ \mathrm{ml}\right)$. After $24 \mathrm{~h}$, a mixture of $3 \mu \mathrm{g} \mathrm{miR}-505$ (Lenti-miR-505, 5'-CGUCAACACUUGCUGGUUUCCU-3') 
Table III. Association of miR-505 with the clinicopathological features of patients.

\begin{tabular}{|c|c|c|c|c|}
\hline \multirow[b]{2}{*}{ Variables } & \multirow{2}{*}{$\begin{array}{l}\text { No. of cases } \\
\quad(n=21)\end{array}$} & \multicolumn{2}{|c|}{ miR-505 expression } & \multirow[b]{2}{*}{ P-value } \\
\hline & & Low $(n=13)$ & High $(n=8)$ & \\
\hline \multicolumn{5}{|l|}{ Age, years } \\
\hline$<60$ & 12 & 7 & 5 & \multirow[t]{2}{*}{0.681} \\
\hline$\geq 60$ & 9 & 6 & 3 & \\
\hline \multicolumn{5}{|l|}{ Sex } \\
\hline Male & 15 & 10 & 5 & \multirow[t]{2}{*}{0.477} \\
\hline Female & 6 & 3 & 3 & \\
\hline \multicolumn{5}{|l|}{ Tumor size, cm } \\
\hline$\geq 5$ & 13 & 10 & 3 & \multirow[t]{2}{*}{$0.049^{\mathrm{a}}$} \\
\hline$<5$ & 8 & 3 & 5 & \\
\hline \multicolumn{5}{|l|}{ TNM stage (23) } \\
\hline I-II & 11 & 4 & 7 & \multirow[t]{2}{*}{$0.011^{\mathrm{a}}$} \\
\hline III-IV & 10 & 9 & 1 & \\
\hline \multicolumn{5}{|l|}{ Distant metastasis } \\
\hline No & 10 & 3 & 7 & \multirow[t]{2}{*}{$0.004^{\mathrm{a}}$} \\
\hline Yes & 11 & 10 & 1 & \\
\hline \multicolumn{5}{|c|}{ Histological type (23) } \\
\hline Squamous & 9 & 6 & 3 & \multirow[t]{2}{*}{0.697} \\
\hline Adenocarcinoma & 12 & 7 & 5 & \\
\hline
\end{tabular}

${ }^{a} \chi^{2}$ test. TNM, Tumor-Node Metastasis; miR, microRNA.

or Control (Lenti-control, 5'-UCAUCGUAUCAGCUA UAU CGCA-3') (Guangzhou RiboBio Co., Ltd.), Lipofectamine 2000 (DNA:Lipofectamine 2000, 1:1), and Opti-MEM was added to the cells for $6 \mathrm{~h}$. Cells with stable expression were obtained following culturing in Dulbecco's modified Eagle's medium for 12 days. These vectors contain a Neomycin resistance cassette, which was used for mammalian cell clone selection and maintenance. Independent clones were picked and grown individually. RNA was isolated using a mirVana miRNA Isolation kit (Ambion; Thermo Fisher Scientific, Inc.), following the manufacturer's protocols. The expression levels of miR-505 were determined by qPCR with a SYBR ${ }^{\circledR}$-Green PCR Master Mix kit according to the manufacturer's protocols. Tumor size was measured every 5 days with calipers following injection, and the tumor volume was calculated based on formula: $0.5 \mathrm{x}$ (greatest length $\mathrm{x}$ greatest width $^{2}$ ). Tumor weight was measured using an electronic scale, and the Student's t-test was used to compare tumor growth among groups. All mice were euthanized with $\mathrm{CO}_{2}$ at the end of 30 days following implantation. All animals received human care according to the Institutional Animal Care and Treatment Committee of Qingdao Municipal Hospital.

Statistics analysis. Statistical analysis was performed using GraphPad Prism v.5.0 (GraphPad Software, Inc., San Diego, CA, USA). All data are presented as the mean \pm standard deviation, and the experiments were repeated three times independently. Differences were analyzed with Student's t-test between two paired groups. For comparisons of three or more groups, one-way analysis of variance was followed by the Bonferroni post hoc test for comparison of two selected treatment groups; the Dunnett's post-hoc test was used for comparisons of the other treatment groups with the corresponding controls. Associations between miR-505 expression and clinicopathological characteristics were assessed using the $\chi^{2}$ test. $\mathrm{P}<0.05$ was considered to indicate a statistically significant difference.

\section{Results}

miR-505 is downregulated in NSCLC tissues and cell lines. The level of miR-505 was determined in 21 paired NSCLC tissues as well as 6 cell lines using a RT-qPCR assay. As depicted in Fig. 1A, miR-505 was significantly reduced in NSCLC tissues, compared with the matched adjacent non-cancerous controls, which is significantly negatively associated with large tumor size, TNM stage and distant metastasis in patients with NSCLC (Table III). Compared with the human normal lung epithelial cells BEAS-2B, the level of miR-505 in different lung cancer cell lines (including A549, H1066, H460, H522 and SPC-A1) was significantly reduced (Fig. 1B).

miR-505 serves as a suppressor gene in NSCLC cells. To investigate the role of miR-505 in NSCLC cells, gain- and loss-of-function experiments were performed to analyze proliferation, cell cycle, migration, invasion, apoptosis and EMT in A549 and H460 cells. miR-505 overexpression (pri-miR-505) 
A

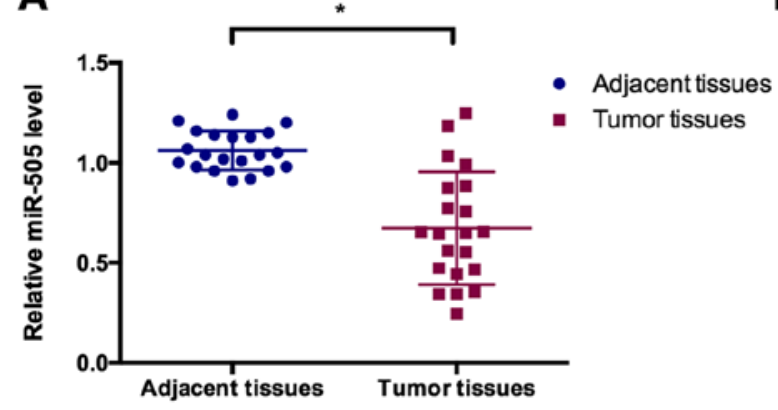

B

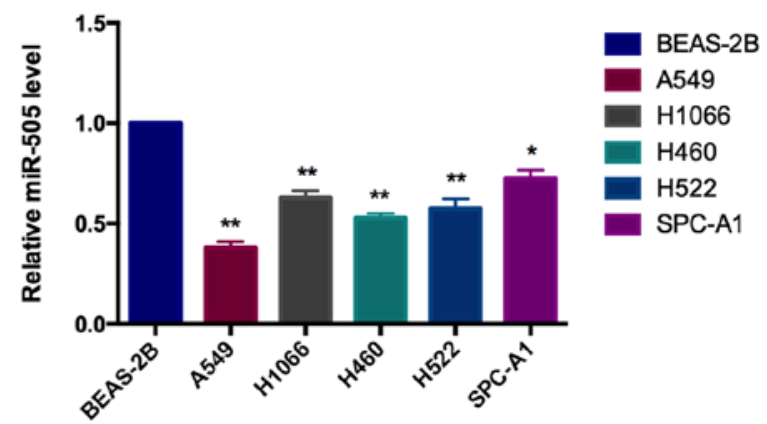

Figure 1. miR-505 is downregulated in NSCLC. (A) A RT-qPCR assay demonstrated the relative miR-505 expression levels in NSCLC and adjacent non-cancerous tissues, which are normalized to values in the control group (equal to 1 ). ${ }^{*} \mathrm{P}<0.05$ vs. control group. (B) A RT-qPCR assay indicated the relative miR-505 expression levels in NSCLC cells and the BEAS-2B cell line, which are normalized to values in the control group (equal to 1$)$. $\mathrm{P}<0.05$ and ${ }^{* *} \mathrm{P}<0.01$ vs. the $\mathrm{BEAS}-2 \mathrm{~B}$ cell line. Data are presented as mean \pm standard deviation. The experiments were repeated three times. NSCLC, non-small cell lung cancer; miR, microRNA.

and knockdown vectors (ASO-miR-505) was constructed and the transfection efficiencies were validated with a RT-qPCR assay. The relative miR-505 level was significantly increased by pri-miR-505 transfection, compared with the pcDNA3 control. However, the relative miR-505 level was significantly decreased upon ASO-miR-505 treatment, compared with ASO-NC treatment in A549 and H460 cells (Fig. 2A).

To determine the effects of miR-505 on cell proliferation, CCK- 8 and colony formation assays were performed. In CCK-8 analysis, the cell viability was measured at $0,24,48$ and $72 \mathrm{~h}$ post-transfection, presented as the OD450 value in Fig. $2 \mathrm{~B}$. Pri-miR-505 significantly inhibited the cell viability in A549 and H460 cells, compared with the pcDNA3 group, while ASO-miR-505 significantly increased the cell viability in these cell lines, compared with the ASO-NC group (Fig. 2B). Colony formation analyses provided the similar results. As indicated in Fig. 2C, overexpression of miR-505 significantly decreased the colony formation ability, compared with the pcDNA3 group, while inhibition of miR-505 could significantly increase the colony formation ability, compared with the ASO-NC group (Fig. 2C).

Cell cycle analyses by flow cytometry revealed that miR-505 overexpression caused an increase in cells at the G0/G1 phase and a decrease in cells at the $\mathrm{S}$ phase, while miR-505 knockdown induced a decrease in cells at the G0/G1 phase and the increase in cells at the S phase (Fig. 2D). Transwell migration and Matrigel invasion assays were performed to investigate the effects of miR-505 on cell migration and invasion, respectively. As indicated in Fig. 2E, it was observed that the migration and invasion capacities was decreased by overexpression of miR-505, and the migration and invasion abilities were enhanced by miR-505 inhibition in A549 and H460 cells (Fig. 2E). Additionally, the EMT markers were detected by western blot analysis. As expected, when miR-505 was overexpressed, the epithelial marker E-cadherin exhibited an increased expression, while the mesenchymal marker vimentin exhibited a decreased expression in both cell lines. However, when miR-505 was inhibited, the epithelial marker E-cadherin decreased and the mesenchymal marker vimentin increased, compared with their respective controls (Fig. 2F).

As depicted in Fig. 2G, overexpression of miR-505 significantly increased apoptosis, while inhibition of miR-505 significantly decreased the cell apoptosis in A549 and H460 cells (Fig. 2G). The expression of apoptosis inhibitor B-cell lymphoma $2(\mathrm{Bcl} 2)$ was decreased upon miR-505 overexpression and increased while inhibiting miR-505. Furthermore, it was also demonstrated that the increased expression of cleaved caspase 3 and cleaved poly (ADP) ribose polymerase (PARP) by overexpression of miR-505, and the opposite results obtained from the inhibition of miR-505 (Fig. 2H).

miR-505 directly targets MAP3K3 in NSCLC cells. By bioinformatics analysis, the putative targets of miR-505 were analyzed and MAP3K3 was selected for further validation. Fig. 3A depicts the alignment of miR-505 binding to the 3'UTR of MAP3K3. The EGFP reporter vector was contrasted to verify the direct binding of miR-505 and MAP3K3. By annealing oligos and ligation to the vector, the putative miR-505 binding site sequences was closed downstream of the EGFP to construct the wild type and mutated form of the EGFP reporter vectors, as indicated in Fig. 3B. By co-transfection with pri-miR-505 or ASO-miR-505 and MAP3K3 3'UTR, the EGFP intensities were measured. As depicted in Fig. 3C, it was observed that the EGFP intensities following co-transfection with the wild-type MAP3K3 3'UTR reporter vector and pri-miR-505 or ASO-miR-505were significantly decreased and increased, respectively, compared with their respective controls (Fig. 3C). When the co-transfection with the mutated form of the reporter vector was performed, there were no significant changes in the EGFP intensities by modulating the expression of miR-505.

Subsequently, the expression levels of MAP3K3 were determined in clinical samples. As depicted in Fig. 3D, there was significantly upregulated expression of MAP3K3 in lung cancer tissues, compared with the matched adjacent normal tissues (Fig. 3D). The expression levels of miR-505 were also modulated in A549 and H460 cells, and the MAP3K3 level at the mRNA and protein levels were detected by RT-qPCR and western blot analysis, respectively. RT-qPCR assays revealed the significantly decreased MAP3K3 mRNA level upon pri-miR-505 transfection and significantly increased MAP3K3 level by inhibition miR-505 in A549 and H460 cells (Fig. 3E). The similar results of MAP3K3 protein levels were indicated in Fig. 3F. 
A
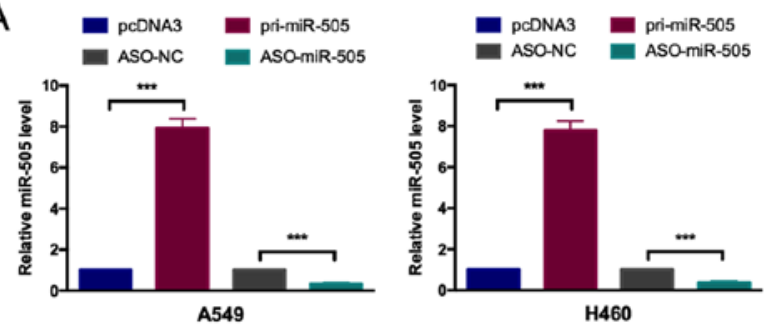

B
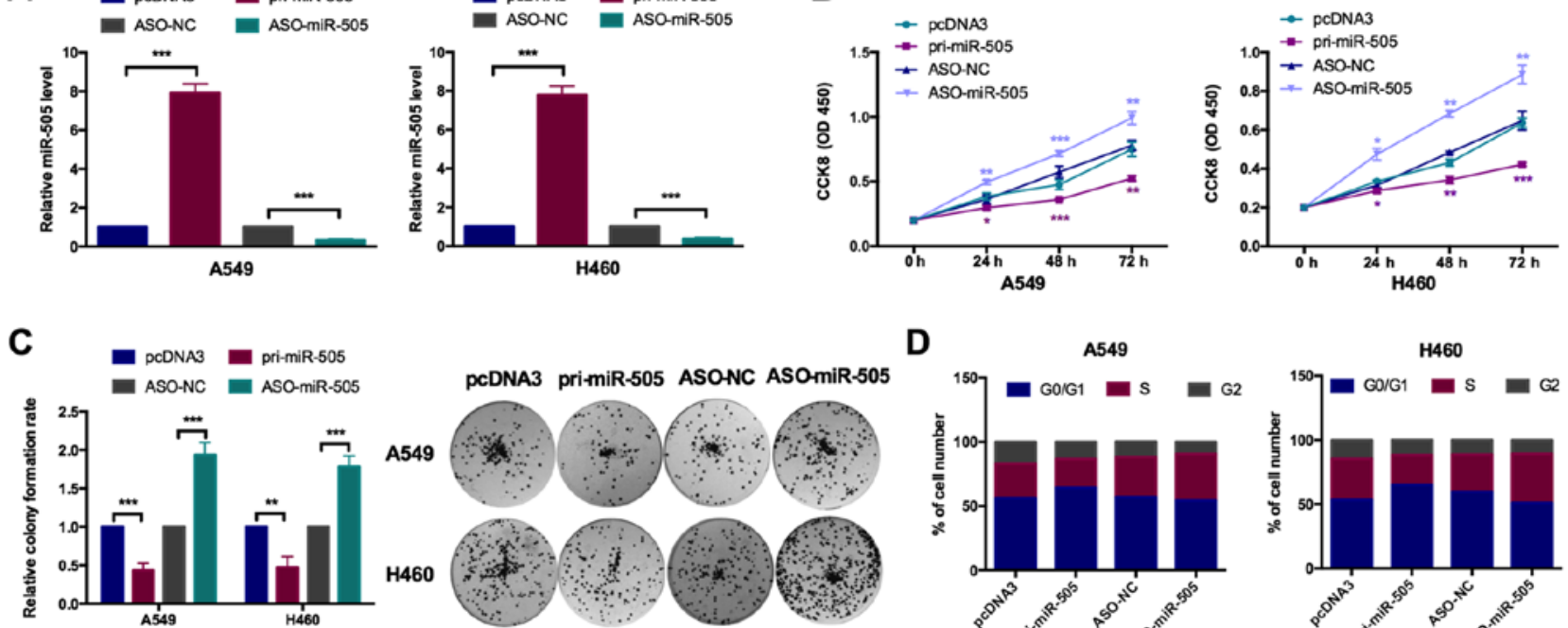

pcDNA3 pri-miR-505 ASONC ASOMIR-505
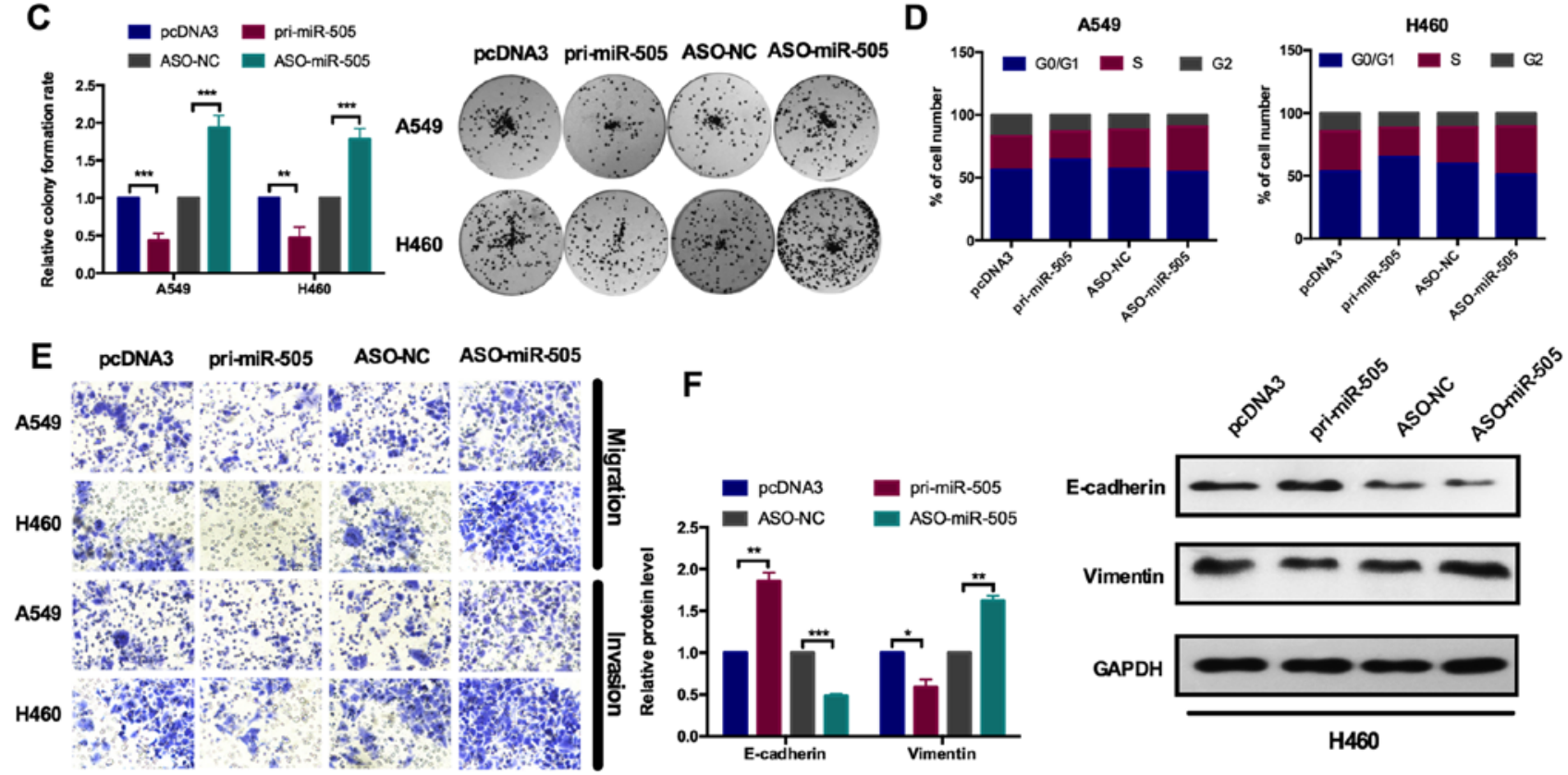

GAPDH
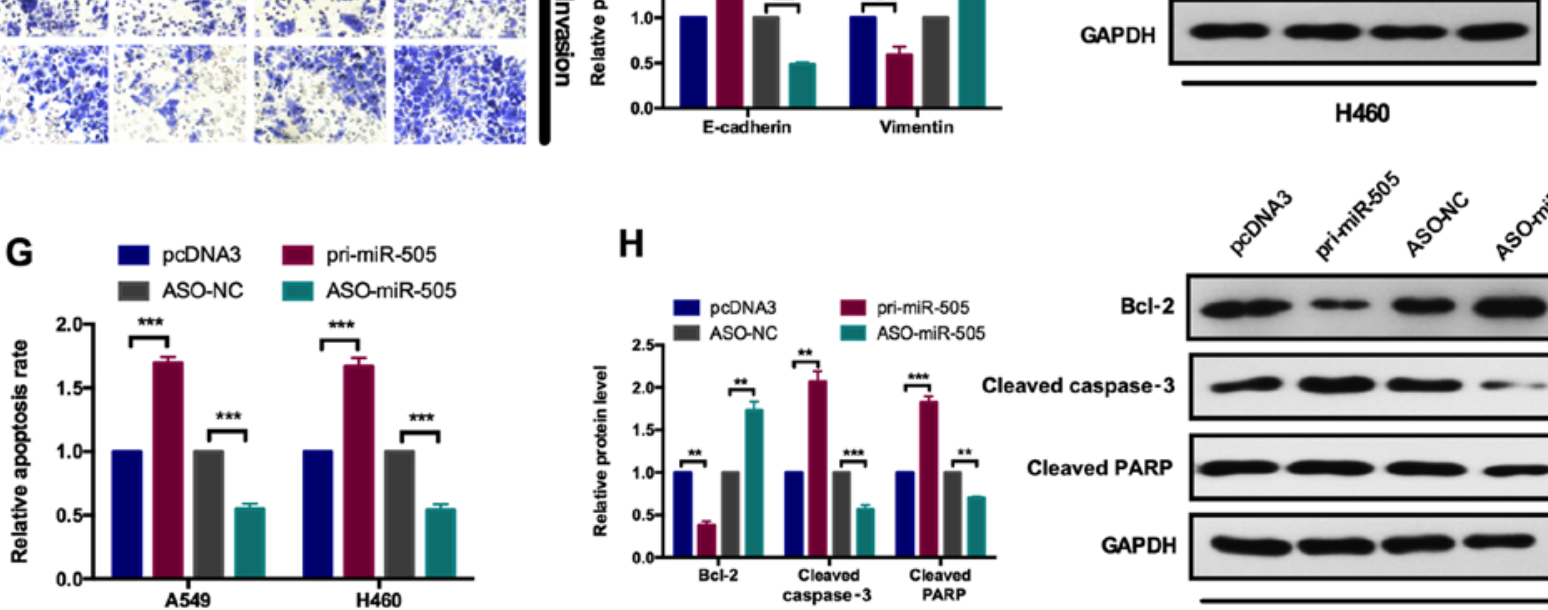

H

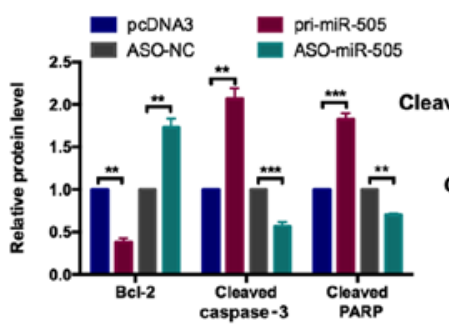

$\mathrm{Bcl}-2$
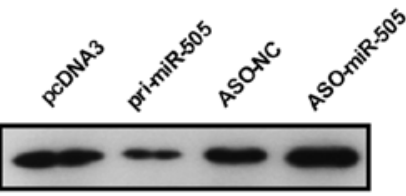

Figure 2. miR-505 inhibits cell proliferation and the epithelial-mesenchymal transition process. (A) A reverse transcription-quantitative polymerase chain reaction assay demonstrated the efficiency of miR-505 overexpression and knockdown plasmids in A549 and H460 cells. Cells were transfected with the pri-miR-505 vector or ASO-miR-505 vector and the control groups, respectively. ${ }^{* * *} \mathrm{P}<0.001$ vs. pcDNA3 or ASO-NC group. (B) The role of miR-505 on A549 and $\mathrm{H} 460$ cellular viabilities was determined with a Cell Counting Kit-8 assay. Overexpression of miR-505 inhibited cell viability and knockdown of miR-505 promoted cell viability. ${ }^{*} \mathrm{P}<0.05,{ }^{* *} \mathrm{P}<0.01$ and ${ }^{* * * *} \mathrm{P}<0.001$ vs. pcDNA3 for pri-miR-505 or ASO-NC for ASO-miR-505. (C) Relative colony formation rates of A549 and $\mathrm{H} 460$ cells with the indicated transfection were determined with a colony formation assay. Overexpression of miR-505 inhibited colony formation ability and knockdown of miR-505 promoted colony formation ability. ${ }^{* *} \mathrm{P}<0.01$ and ${ }^{* * *} \mathrm{P}<0.001$ vs. pcDNA3 or ASO-NC group. (D) Flow cytometry cell cycle assay demonstrated the role of miR-505 on the cell cycle in A549 and H460 cells. Overexpression of miR-505 decreased the number of A549 and H460 cells in the S and G2 phases, and decreased the number of cells in the G1 phase. Knockdown of miR-505 increased the number of HeLa and SiHa cells in the S and G2 phases, and decreased the number of cells in the G1 phase. (E) Transwell migration and Matrigel invasion assays indicated that overexpression of miR-505 suppressed cell migration and invasion ability in A549 and H460 cells. (F) Western blot assays demonstrated the protein levels of E-cadherin and vimentin following transfection with pri-miR-505 or ASO-miR-505 vectors in A549 and $\mathrm{H} 460$ cells. ${ }^{*} \mathrm{P}<0.05,{ }^{* * *} \mathrm{P}<0.01$ and ${ }^{* * * *} \mathrm{P}<0.001$ vs. pcDNA3 or ASO-NC group. (G) Flow cytometry apoptosis assay indicated the role of miR-505 on apoptosis in A549 and H460 cells transfected with pri-miR-505 vector or ASO-miR-505 vector and the control group. ${ }^{* * *} \mathrm{P}<0.001$ vs. pcDNA3 or ASO-NC group. (H) Western blot assays demonstrated the protein levels of Bcl2, and cleaved caspase-3 and PARP following transfection with pri-miR-505 or ASO-miR-505 in A549 and H460 cells. ${ }^{* *} \mathrm{P}<0.01$ and ${ }^{* * *} \mathrm{P}<0.001$ vs. pcDNA3 or ASO-NC group. Data are presented as mean \pm standard deviation. The experiments were repeated three times. miR, microRNA; ASO, antisense oligonucleotide; NC, negative control; Bcl2, B-cell lymphoma 2; PARP, poly (ADP) ribose polymerase.

MAP3K3 serves an oncogenic role and miR-505 neutralizes its effects in NSCLC cells. To further confirm the effects of miR-505 on cell proliferation, cell cycle, apoptosis, migra- tion, invasion and EMT in NSCLC cells were mediated by MAP3K3, rescue experiments were performed. The transfection efficiency of MAP3K3 expression vectors was determined. 
A



B

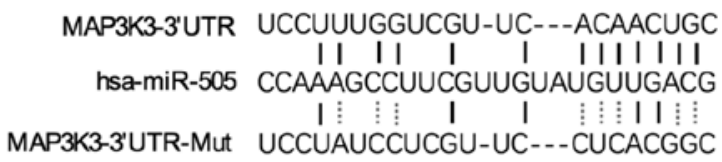

C
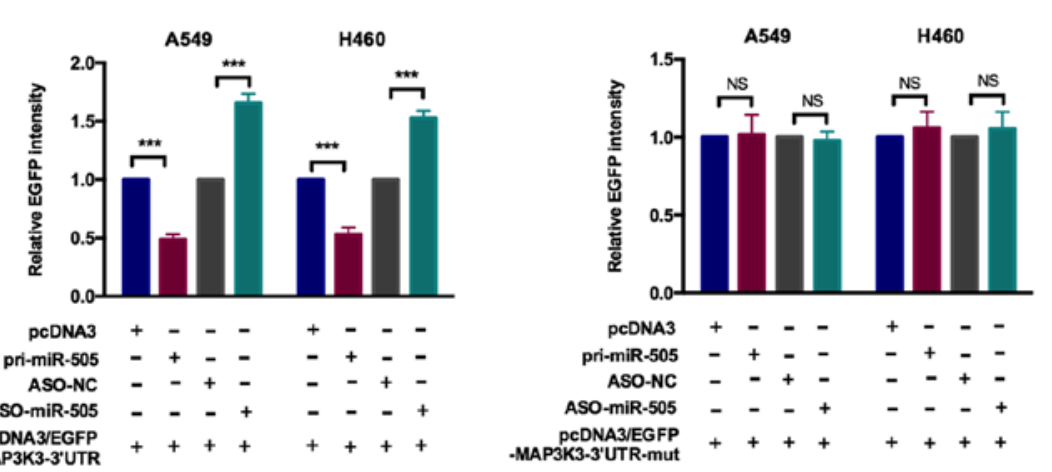

D

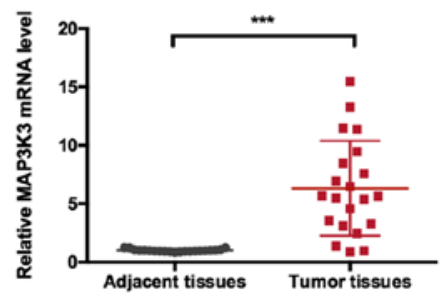

$\mathbf{E}$

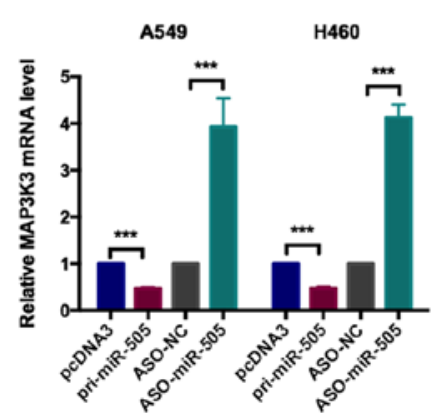

$\mathbf{F}$

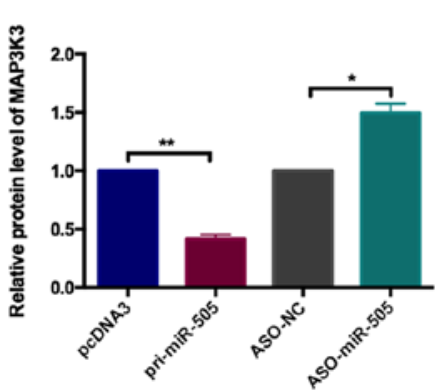

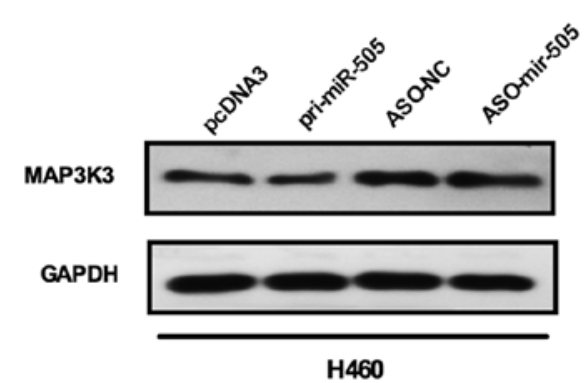

Figure 3. miR-505 directly targets MAP3K3. (A) The predicted miR-505 binding sites in MAP3K3 mRNA using microRNA.org were depicted. (B) The sequence of MAP3K3-3'UTR-Mut was depicted. (C) A549 and H460 cells were co-transfected with pcDNA3/EGFP-MAP3K3 3'-UTR or 3'-UTR-mut and pri-miR-505 or ASO-miR-505 and the control group. The EGFP intensity was determined with a spectrophotometer, and the value of the control group (pcDNA3 or ASO-NC) was set to $1 .{ }^{* * *} \mathrm{P}<0.001$ vs. pcDNA3 or ASO-NC group. (D) A RT-qPCR assay demonstrated the mRNA level of MAP3K3 in NSCLC and the adjacent normal tissues. The mRNA level of MAP3K3 was upregulated in tumor tissues. ${ }^{* * *} \mathrm{P}<0.001 \mathrm{vs}$. the adjacent tissues. (E) MAP3K3 mRNA level in A549 and H460 cells with pri-miR-505 or ASO-miR-505 and the control group transfection were measured with a RT-qPCR assay. ${ }^{* * *} \mathrm{P}<0.001$ vs. pcDNA3 or ASO-NC group. (F) MAP3K3 protein level in A549 and H460 cells transfected with pri-miR-505 or ASO-miR-505 and the respective controls were determined with a western blot assay. ${ }^{*} \mathrm{P}<0.05$ and ${ }^{* *} \mathrm{P}<0.01$ vs. pcDNA3 or ASO-NC group. Data are presented as mean \pm standard deviation. The experiments were repeated three times. miR, microRNA; ASO, antisense oligonucleotide; NC, negative control; RT-qPCR, reverse transcription-quantitative polymerase chain reaction; MAP3K3; mitogen-activated protein kinase kinase kinase 3; Mut, mutation; EGFP, enhanced green fluorescent protein; UTR, untranslated region.

As depicted in Fig. 4A, the mRNA level of MAP3K3 was significantly increased upon overexpression of MAP3K3, compared with the empty vector control pcDNA3, in A549 and H460 cells. Subsequently, co-transfection experiments with MAP3K3 and miR-505 expression vectors were performed and the combined effects of MAP3K3 and miR-505 together were detected. As indicated in Fig. $4 \mathrm{~B}$ and C, overexpression of MAP3K3 increased cell proliferation, while overexpression of MAP3K3 and miR-505 together decreased the enhanced role induced by MAP3K3, as assessed by CCK-8 and colony formation assays individually. The cell cycle analysis revealed that MAP3K3 induced the increase of cells in the $S$ phase and the decrease of cells in the G0/G1 phase, while combination of miR-505 and MAP3K3 eliminated the oncogenic roles caused by MAP3K3 (Fig. 4D). Transwell migration and Matrigel invasion assays, and western blot analysis was used to detect the EMT markers, which demonstrated the increased migration and invasion capabilities, and decreased expression of E-cadherin and increased expression of vimentin upon overexpressing MAP3K3. Furthermore, cells treated with MAP3K3 and miR-505 together had increased effects on migration, invasion and EMT, caused by MAP3K3, reduced back to the normal control level (Fig. 4E and F). Similarly, the apoptosis detected by flow cytometry analysis and western blot assays indicated the inhibition effects induced by MAP3K3, which was opposite to the effects induced by miR-505, while combination of MAP3K3 and miR-505 overexpression abolished the inhibition effects induced by MAP3K3, as indicated by the relative apoptosis rates assessed by flow cytometry (Fig. 4G) and presented by the increased expression of $\mathrm{Bcl} 2$ as well as the decreased expressions of cleaved caspase 3 and cleaved PARP (Fig. 4H). These results demonstrated that MAP3K3 mediated the role of miR-505 on cell proliferation, cell cycle arrest, apoptosis, migration, invasion as well as EMT progress in NSCLC cells. 
A

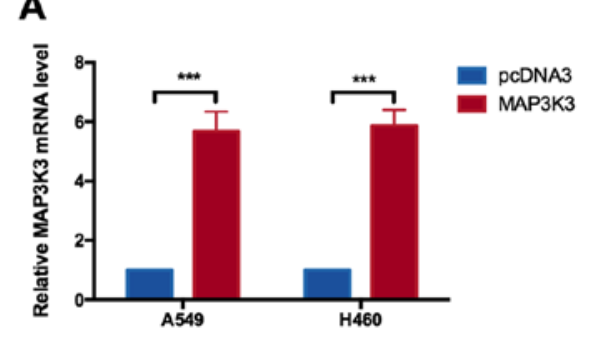

B

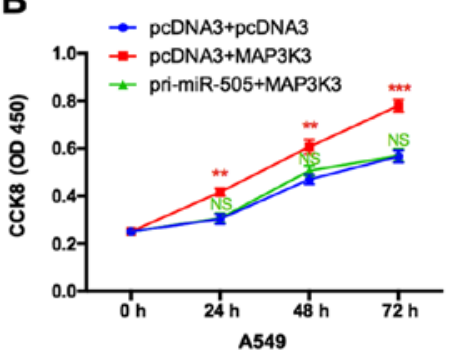

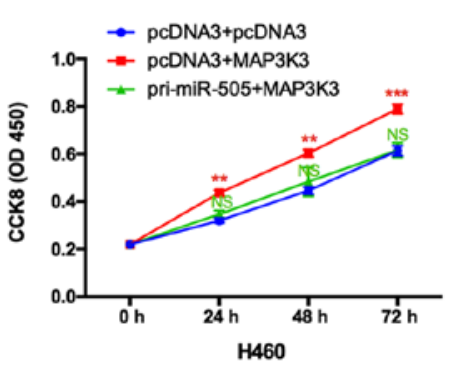


G

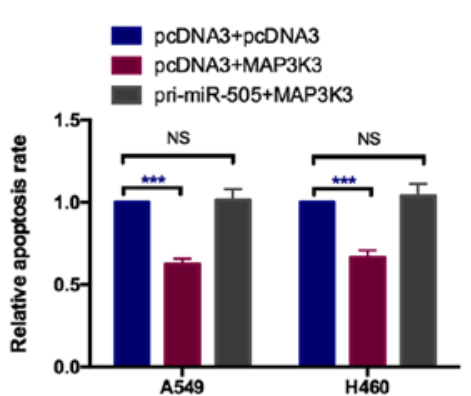

H
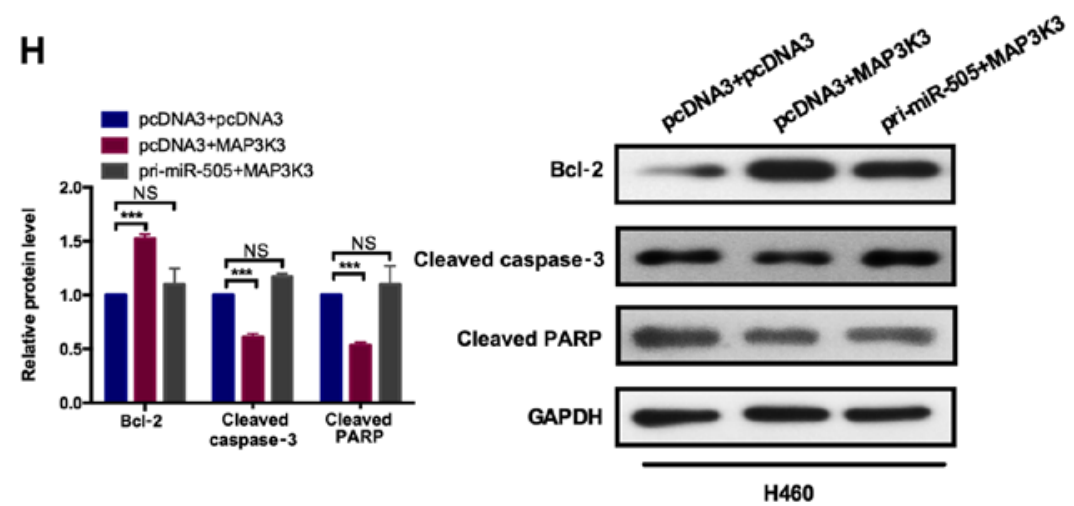

Figure 4. MAP3K3 promotes cell proliferation and the epithelial-mesenchymal transition process. (A) A reverse transcription-quantitative polymerase chain reaction assay demonstrated the efficiency of the overexpression plasmid of MAP3K3 in A549 and H460 cells. (B) The indicated transfection on A549 and H460 cellular viabilities was determined with a Cell Counting Kit-8 assay. A549 and H460 cells were transfected with the indicated combinations of pcDNA3 and MAP3K3 or pri-miR-505 and MAP3K3 or the control group. MAP3K3 overexpression promoted cell viability. NS vs. pri-miR-505 and MAP3K3; ${ }^{* *} \mathrm{P}<0.01,{ }^{* * *} \mathrm{P}<0.001$ vs. pcDNA3 and MAP3K3 group. (C) Relative colony formation rates of A549 and $\mathrm{H} 460$ cells with the indicated transfection were determined with a colony formation assay. MAP3K3 overexpression promoted colony formation ability. NS vs. pri-miR-505 and MAP3K3; ${ }^{* * *} \mathrm{P}<0.001 \mathrm{vs}$. pcDNA3 and MAP3K3 group. (D) Flow cytometry cell cycle assay demonstrated the indicated transfection on the cell cycle in A549 and H460 cells. MAP3K3 overexpression increased the number of A549 and H460 cells in the S and G2 phases, and decreased the number of cells in the G1 phase. (E) Transwell migration and Matrigel invasion assays indicated that MAP3K3 promoted and pri-miR-505 and MAP3K3 rescued the MAP3K3 mediated cell migration and invasion ability in A549 and H460 cells. (F) Western blot assays demonstrated the protein levels of E-cadherin and vimentin following transfection with the indicated transfection in A549 and H460 cells. NS vs. pri-miR-505 and MAP3K3; ${ }^{* * *} \mathrm{P}<0.001$ vs. pcDNA3 and MAP3K3 group. (G) Flow cytometry apoptosis assay demonstrated the indicated transfection on apoptosis in A549 and H460 cells. MAP3K3 inhibited cell apoptosis. NS vs. pri-miR-505 and MAP3K3; ${ }^{* * *}$ P $<0.001$ vs. pcDNA3 and MAP3K3 group. (H) Western blot assays indicated the protein levels of Bcl2, and cleaved caspase-3 and PARP following transfection with the indicated transfection in A549 and H460 cells. MAP3K3 promoted Bc12 and inhibited cleaved caspase-3 and PARP expression. NS vs. pri-miR-505 and MAP3K3; ${ }^{* * *} \mathrm{P}<0.001$ vs. pcDNA3 and MAP3K3 group. Data are presented as mean \pm standard deviation. The experiments were repeated three times. miR, microRNA; ASO, antisense oligonucleotide; NC, negative control; MAP3K3; mitogen-activated protein kinase kinase kinase 3; Bcl2, B-cell lymphoma 2; PARP, poly (ADP) ribose polymerase; OD, optical density. 
miR-505 regulates the AKT/NF $\kappa B$ pathway through MAP3K3. $\mathrm{MAP} 3 \mathrm{~K} 3$, as a member of mitogen-activated protein kinase (MAPK) family, could interact with AKT to active the $\mathrm{NF} \kappa \mathrm{B}$ signaling pathway (26). It was determined whether miR-505 was also involved in AKT/NFkB pathways via MAP3K3 by western blot analysis to analyze the expression level of AKT (total AKT and phosphorylated form of AKT) and its downstream target IKB kinase $\alpha$ (IKK $\alpha$ ) and IKK $\beta$ as well as the activation of the $\mathrm{NF \kappa B}$ pathway.

Firstly, the level of miR-505 in NSCLC cells was modulated by gain- and loss-of-function experiments and the expression levels of the indicated molecules were detected. As indicated in Fig. 5A, overexpression of miR-505 significantly inhibited the phosphorylation of AKT (pAKT) but not the total AKT, and the expression of its downstream targets IKK $\alpha$ and IKK $\beta$ was also significantly decreased by miR-505 overexpression (Fig. 5A). To further evaluate the effects of miR-505 on $\mathrm{NF} \kappa \mathrm{B}$ pathway activation, the nuclear and cytoplasmic cell lysates was isolated and the expression level of p50 and p65 was determined by western blot analysis. It was demonstrated that nuclear p50 and p65 expression was significantly decreased while cytoplasmic p50 and p65 expression was significantly increased upon overexpression of miR-505 in cells (Fig. 5B), indicating the activation of the NFKB pathway was inhibited by miR-505 overexpression. However, miR-505 knockdown resulted in the activation of AKT (increased expression of pAKT), increased expression of IKK $\alpha$ and IKK $\beta$ as well as the elevated expression of nuclear $\mathrm{p} 50$ and $\mathrm{p} 65$, and decreased expression of cytoplasmic p50 and p65 (Fig. 5A and B).

Subsequently, co-transfection with miR-505 and MAP3K3 in NSCLC cells was performed to re-evaluate the effects of miR-505 on the AKT/NFkB pathway activation. As depicted in Fig. 5C and D, overexpression of miR-505 significantly inhibited $\mathrm{AKT} / \mathrm{NF}$ KB pathway activation, presented as decreased expression of pAKT, IKK $\alpha$, IKK $\beta$, and nuclear $\mathrm{p} 50$ and $\mathrm{p} 65$, and increased expression of cytoplasmic p50 and p65. However, ectopic expression of MAP3K 3 in the presence of miR-505 counteracted the effects induced by miR-505 to the normal control level, presented as increased expression levels of pAKT, IKK $\alpha$, $\mathrm{IKK} \beta$, and nuclear $\mathrm{p} 50$ and $\mathrm{p} 65$, and decreased expression of cytoplasmic p50 and p65, compared with only miR-505 overexpression (Fig. 5C and D). Additionally, an immunofluorescence assay in A549 cells demonstrated the nuclear distribution of p50 and p65 transfected with miR-505 was reduced, compared with the pcDNA3 group. The nuclear distribution of p50 and p65 transfected with MAP3K3 was increased, compared with the pcDNA3 group. Furthermore, co-transfection with miR-505 and MAP3K3 rescued the role of miR-505 and MAP3K3 induced in cells (Fig. 5E). These results provided the direct evidence that miR-505 inhibited the AKT/NFkB pathway by downregulating MAP3K3 expression in NSCLC cells.

miR-505 inhibits tumor growth in vivo. To verify whether miR-505 regulates the tumor growth in vivo, miR-505-overexpressing and control A549 cells were subcutaneously transplanted into the right flank of mice. After 30 days, it was determined that stable transfection of lenti-miR-505 in A549 cells significantly inhibited the tumor growth (Fig. 6A and B) and significantly decreased the tumor weight (Fig. 6C and D). The RT-qPCR assay demonstrated that the level of miR-505 in the xenograft was upregulated in the miR-505-treated group (Fig. 6E). Additionally, the RT-qPCR and western blot assays indicated the mRNA and protein level of MAP3K3 in the xenograft was significantly downregulated in the miR-505-treated group (Fig. 6F and G). These data indicated that miR-505 inhibited tumor growth in vivo.

\section{Discussion}

miRNA expression signature for lung cancer was characterized by previous studies $(27,28)$. Recently, a number of individual studies reported the dysregulated miRNAs in NSCLC and the functional roles of the individual miRNAs were investigated (29-35). For example, Yang et al (29) reported that miR-183 has a decreased expression level in NSCLC tissues and act as a tumor suppressor by downregulating metastasis associated 1 in NSCLC cells (29). Other miRNAs, including miR-30b (30), miR-485-5p (31), miR-449a (32), miR-1253 (33) and miR-615-3p (34), also exhibit reduced expression levels in NSCLC tissues, compared with the adjacent normal tissues, and could inhibit cell proliferation and invasion in NSCLC cells individually by binding to the 3'UTR of their different targets. Additionally, Ding et al (35) reported that miR-25 was highly expressed in NSCLC tissues, and enhanced cell migration and invasion by inhibiting kruppel like factor 4 in NSCLC cells. These experimental data, including the present results, provide direct evidence that miRNAs are involved in the pathogenesis of NSCLC.

MAP3K3, a family member of serine/threonine protein kinase, acts as an upstream regulator of the MAPK pathway and activated multiple MAPKs, including extracellular regulated kinase 1 (ERK1)/ERK2, c-Jun N-terminal kinase, p38 and ERK5, regulating numerous different cellular functions, including proliferation, migration, immune response and cell cycle $(36,37)$. Additionally, MAP3K3 could active the IKK/NFKB pathway (38). Apart from its roles in the immune responses, MAP3K3 was previously reported to be associated with tumorigenesis. For example, Hasa et al (39) reported that MAP3K3 expression was significantly increased in esophageal dysplasia and esophageal squamous cell carcinoma in comparison with the normal mucosa, and had the potential to serve as a predictor of poor disease prognosis (39). There are 8-20\% patients with breast cancer that harbor MAP3K3 gene amplification, and in vitro and in vivo studies (40) demonstrated that MAP3K3 contributes to breast carcinogenesis and may endow resistance of breast cancer cells to cytotoxic chemotherapy, indicating its potential valuable therapeutic target in patients with MAP3K3-amplified breast cancer (40). A number of studies also evaluated the prognostic applications of MAP3K3 in different types of cancer $(41,42)$. Jia et al (41) reported that MAP3K3 overexpression was observed in $~ 60 \%$ of ovarian carcinoma cases and was significantly associated with histological type, grade and chemotherapy response, indicating that MAP3K3 overexpression may be an independent poor prognostic indicator in ovarian carcinoma. Additionally, He et al (42) investigated the associations between the expression of MAP3K3 and the clinical outcomes in primary lung cancer. Their data indicated that overexpression of MAP3K3 associated with the active immune response and the improved patient survival in patients with lung cancer. 

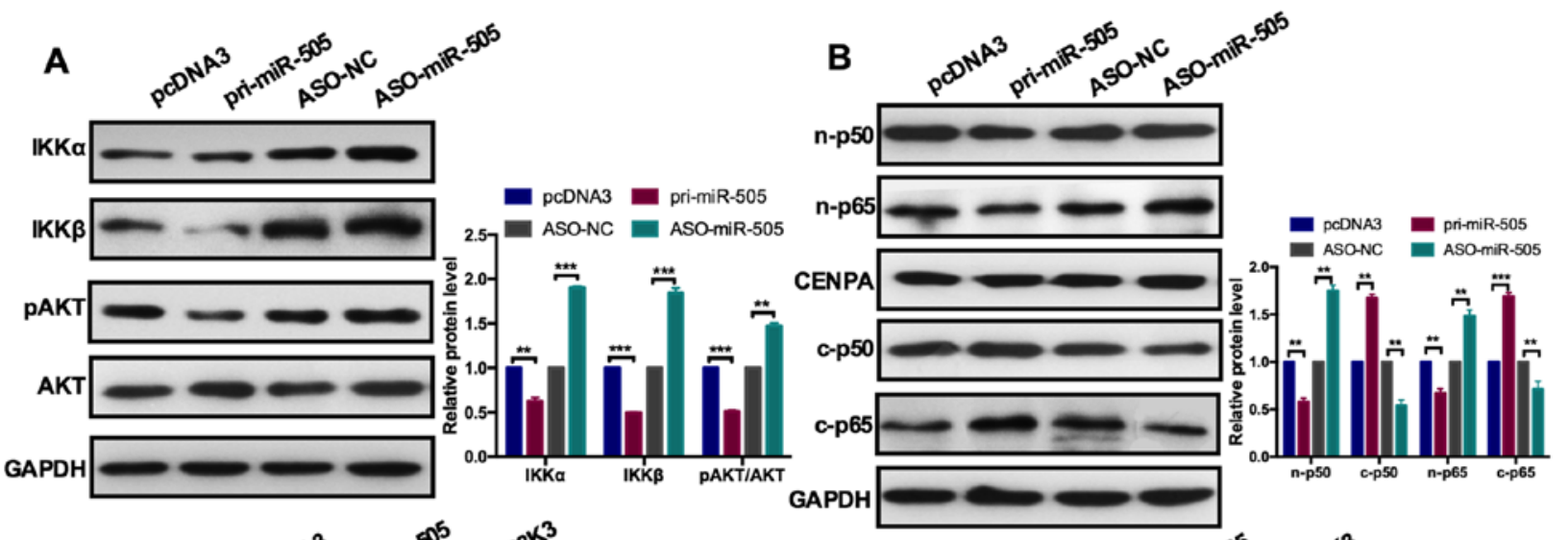
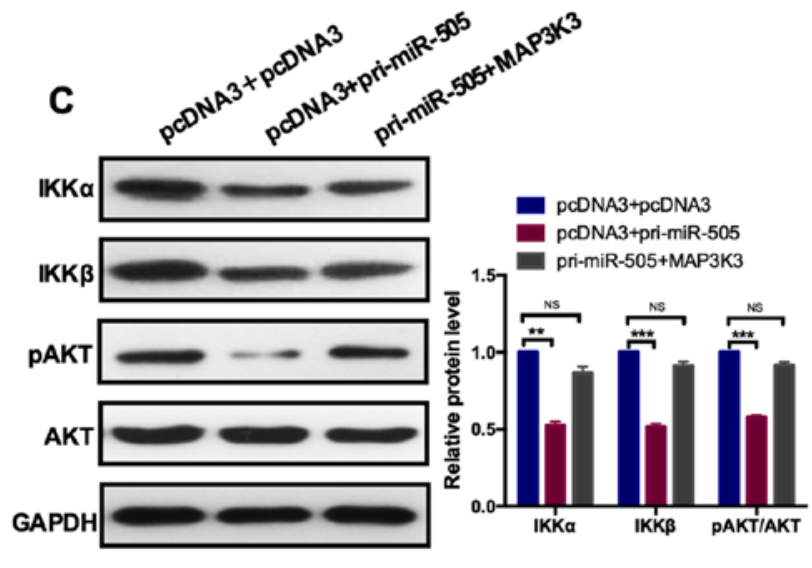

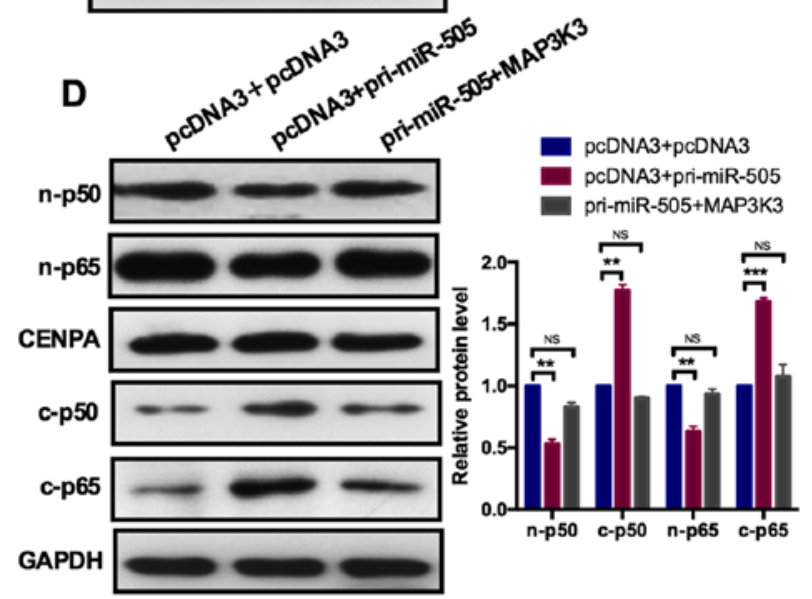

E

DAPI
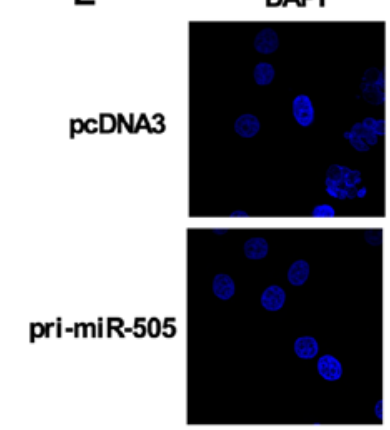

MAP3K3
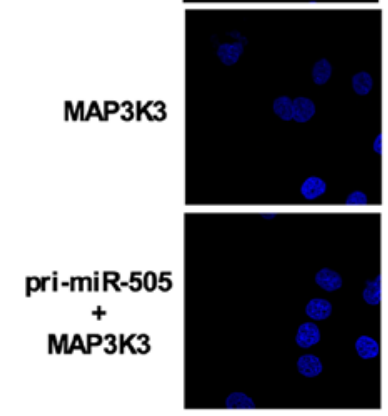

p50


Merged
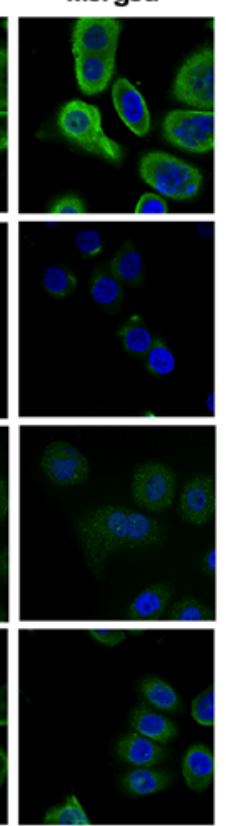

DAPI
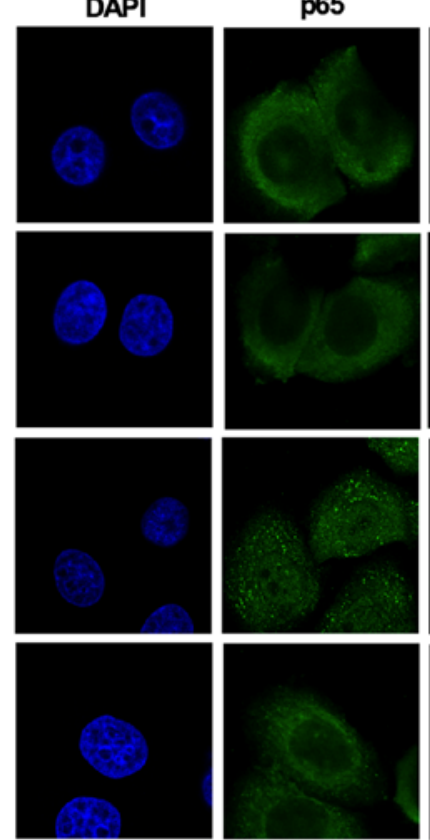

Merged
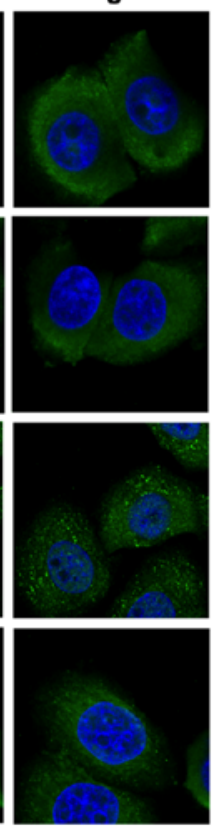

Figure 5. miR-505 inhibits the AKT-nuclear factor- $\mathrm{B}$ pathway through MAP3K3. (A) A western blot assay demonstrated the protein expression levels of IKKa, IKK $\beta$, pAKT, AKT with pri-miR-505 or ASO-miR-505 and the control group in A549 cells. miR-505 overexpression inhibited IKKa, IKK $\beta$ and pAKT expression but not the total AKT expression. ${ }^{* *} \mathrm{P}<0.01$ and ${ }^{* * *} \mathrm{P}<0.001$ vs. pcDNA3 or ASO-NC group. (B) A western blot assay indicated the protein expression levels of n-p50, c-p50, n-p65 and c-p65 with pri-miR-505 or ASO-miR-505 and the control group in A549 cells. miR-505 overexpression inhibited n-p50 and $\mathrm{n}$-p65 expression. ${ }^{* *} \mathrm{P}<0.01$ and ${ }^{* * * *} \mathrm{P}<0.001$ vs. pcDNA3 or ASO-NC group. (C) A western blot assay demonstrated the protein expression levels of IKKa, IKK $\beta$, pAKT, AKT with pcDNA3 and pcDNA3 or pcDNA3 and pri-miR-505 or pri-miR-505 and MAP3K3 in A549 cells. MAP3K3 overexpression rescued the role of miR-505 induced on the expression level of the indicated markers. NS vs. pri-miR-505 and MAP3K $3 ;^{* *} \mathrm{P}<0.01$ and ${ }^{* * *} \mathrm{P}<0.001$ vs. pcDNA3 and pri-miR-505 group. (D) A western blot assay indicated the protein expression levels of n-p50, c-p50, n-p65 and c-p65 with pcDNA3 and pcDNA3 or pcDNA3 and pri-miR-505 or pri-miR-505 and MAP3K3 in A549 cells. NS vs. pri-miR-505 and MAP3K3; ${ }^{* *} \mathrm{P}<0.01$ and ${ }^{* * *} \mathrm{P}<0.001$ vs. pcDNA3 and pri-miR-505 group. (E) An immunofluorescence assay indicated the distribution of p50 and p65 transfected with the indicated plasmids in A549 cells. miR-505 inhibited but MAP3K3 promoted the nuclear distribution of $\mathrm{p} 50$ and $\mathrm{p} 65$. Data are presented as mean \pm standard deviation. The experiments were repeated three times. pAKT, phosphorylated AKT; n-p50, nuclear p50; c-p50, cytoplasmic p50; miR, microRNA; ASO, antisense oligonucleotide; NC, negative control; MAP3K3; mitogen-activated protein kinase kinase kinase 3 ; IKK $\beta$, IкB kinase $\beta$; CENPA, centromere protein $\mathrm{A}$. 
A
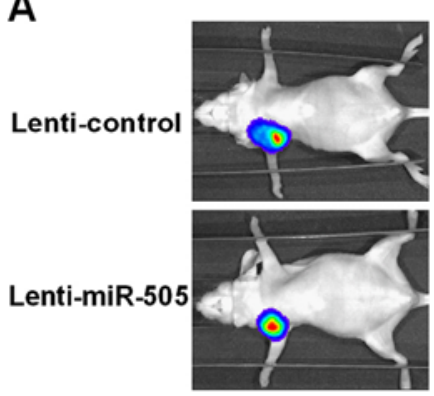

E

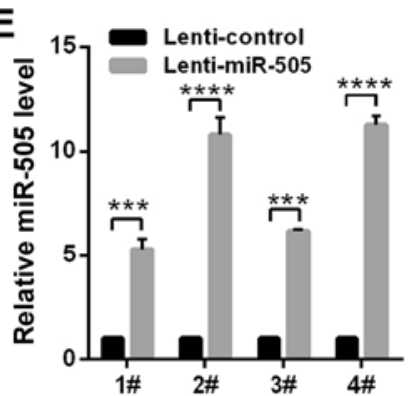

B

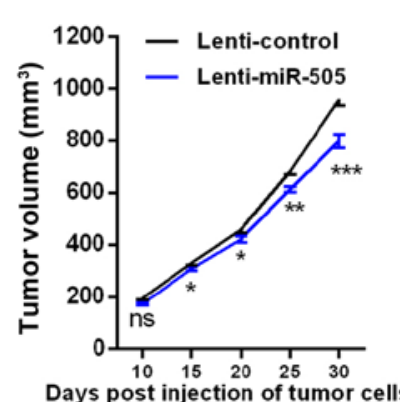

F



C

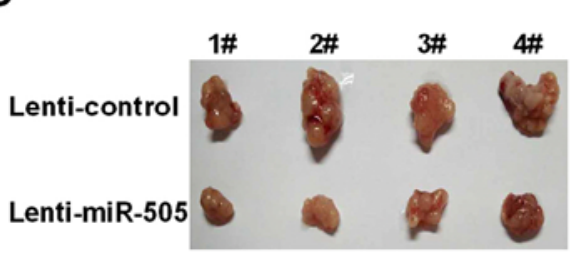

D

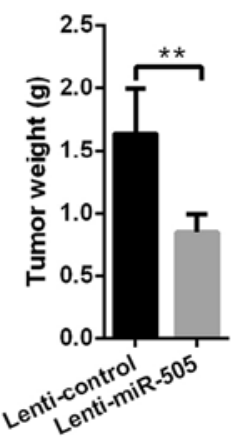

G

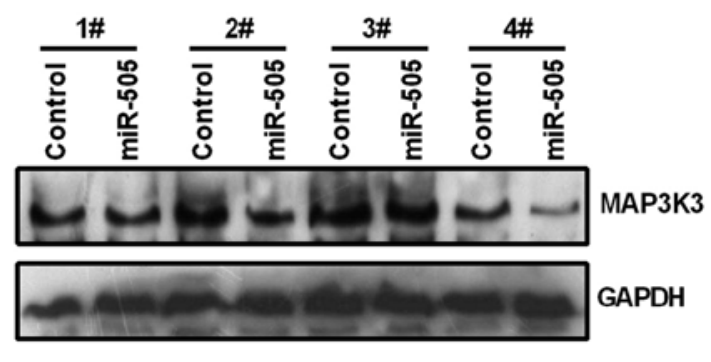

Figure 6. miR-505 inhibits tumor growth in vivo. (A) Compared with the lenti-control group, the tumorigenic ability of A549 cells was inhibited following transfection with lenti-miR-505. (B) The tumor growth rate was significantly decreased following treatment with lenti-miR-505. ${ }^{*} \mathrm{P}<0.05,{ }^{* *} \mathrm{P}<0.01$ and ${ }^{* * *} \mathrm{P}<0.001$ vs. lenti-control. Lenti-miR-505 inhibited (C) tumor size and (D) weight. The $1 \#-4 \#$ represent the number of nude mice used in the present study. ${ }^{* *} \mathrm{P}<0.01$ vs. lenti-control. (E) A RT-qPCR assay detected the level of miR-505 in xenografted tumor tissues. miR-505 was upregulated in tumor tissues. ${ }^{* * *}$ P $<0.001$ and ${ }^{* * * * *} \mathrm{P}<0.0001$ vs. lenti-control. (F) A RT-qPCR assay detected the mRNA level of MAP3K3 in xenografted tumor tissues. The mRNA level of MAP3K3 was upregulated in tumor tissues. ${ }^{* *} \mathrm{P}<0.01$ and ${ }^{* * *} \mathrm{P}<0.001$ vs. lenti-control. (G) A western blot assay detected the protein level of MAP3K 3 in xenografted tumor tissues. The protein level of MAP3K3 was upregulated in tumor tissues. Data are presented as mean \pm standard deviation. The experiments were repeated three times. Lenti, lentivirus; miR, microRNA; RT-qPCR, reverse transcription-quantitative polymerase chain reaction; MAP3K3; mitogen-activated protein kinase kinase kinase 3.

As small regulator RNA molecules, miRNAs serve important roles in regulating gene expression at the post-transcriptional level (43). It had been demonstrated that one gene could be regulated by different miRNAs and one miRNA could regulate hundreds of different genes according to the different cell context (43). Previous studies had identified a number of miRNAs could directly regulate the expression of MAP3K3 (44-46). For example, brain-specific miR-124 is significantly downregulated in LPS-treated BV2 cells and MPTP-induced model of Parkinson's disease, and miR-124 directly inhibits the expression of MAP3K3 by binding to its 3'UTR in the inflammatory pathogenesis of Parkinson's disease (44). Zheng et al (45), reported that miR-188 was upregulated in aged lineage-negative bone marrow cells, enhanced cell senescence by regulating MAP3K3 expression and provided a novel strategy for prevention and treatment of cardiovascular disease. Recently, Zhao et al (46) reported that miR-188 directly targeted MAP3K3 in NSCLC and functioned as a tumor suppressor (46).

In the present study, for the first time, to the best of our knowledge, it was demonstrated that miR-505 was downregulated and MAP3K3 was upregulated in NSCLC tissues, and MAP3K3 was identified as a direct target of miR-505. Additionally, the functional roles of miR-505 were assessed by different assays, and its tumor suppressor functions in NSCLC cells were confirmed in vitro by inhibiting tumor growth and EMT progress. By directly binding to the 3'UTR of MAP3K3, miR-505 inhibited MAP3K3 expression and subsequently inactivated the $\mathrm{AKT} / \mathrm{NF} \mathrm{B}$ pathway, resulting in the decreased expression levels of IKK $\alpha$, IKK $\beta$, pAKT, and nuclear p50 and $\mathrm{p} 65$, as well as the accumulation of the cytoplasmic p50 and p65. By rescue experiments, the tumor suppressor roles of miR-505 mediated directly by MAP3K3 in NSCLC cells were confirmed. MAP3K3 subsequently mediated the inhibition of AKT/NFKB activation induced by overexpression of miR-505, and constructed an indirect regulation axis between miR-505 and the AKT/NFкB pathway. The present data provided evidence of miRNAs involved in the pathogenesis of NSCLC and may serve as valuable biomarkers for clinical applications.

\section{Acknowledgements}

The authors would like to acknowledge the beneficial comments on the present study received from reviewers.

\section{Funding}

No funding was received.

\section{Availability of data and materials}

The datasets used and/or analyzed during the present study are available from the corresponding author on reasonable request.

\section{Authors' contributions}

HT and YH designed the study. WL collated the data, and designed and developed the database. WS performed the data 
analyses and produced the initial draft of the manuscript. HT, QB and WL obtained the results and validated them. All authors read and approved the final manuscript.

\section{Ethics approval and consent to participate}

The present study was approved by the Ethics Committee of Qingdao Municipal Hospital (Qingdao, China) and informed consent was obtained from all patients prior to the study.

\section{Patient consent for publication}

Consent for publication was obtained from the participants.

\section{Competing interests}

The authors declare that they have no competing interests.

\section{References}

1. Siegel RL, Miller KD and Jemal A: Cancer statistics, 2018. CA Cancer J Clin 68: 7-30, 2018.

2. Herbst RS, Heymach JV and Lippman SM: Lung cancer. N Engl J Med 359: 1367-1380, 2008.

3. Abbosh C, Birkbak NJ and Swanton C: Early stage NSCLC challenges to implementing ctDNA-based screening and MRD detection. Nat Rev Clin Oncol 15: 577-586, 2018.

4. Frega S, Bonanno L, Guarneri V, Conte P and Pasello G: Therapeutic perspectives for brain metastases in non-oncogene addicted non-small cell lung cancer (NSCLC): Towards a less dismal future? Crit Rev Oncol Hematol 128: 19-29, 2018.

5. Tsiara A, Liontos M, Kaparelou M, Zakopoulou R, Bamias A and Dimopoulos MA: Implementation of immunotherapy in the treatment of advanced non-small cell lung cancer (NSCLC). Ann Transl Med 6: 144, 2018.

6. Economopoulou P and Mountzios G: The emerging treatment landscape of advanced non-small cell lung cancer. Ann Transl Med 6: 138, 2018.

7. Iorio MV and Croce CM: MicroRNAs in cancer: Small molecules with a huge impact. J Clin Oncol 27: 5848-5856, 2009.

8. Yuan HL, Wang $\mathrm{T}$ and Zhang KH: MicroRNAs as potential biomarkers for diagnosis, therapy and prognosis of gastric cancer. OncoTargets Ther 11: 3891-3900, 2018.

9. Han Y and Li H: miRNAs as biomarkers and for the early detection of non-small cell lung cancer (NSCLC). J Thorac Dis 10: 3119-3131, 2018.

10. Lekka E and Hall J: Noncoding RNAs in disease. FEBS Lett 592: 2884-2900, 2018.

11. Calin GA and Croce CM: MicroRNA-cancer connection: The beginning of a new tale. Cancer Res 66: 7390-7394, 2006.

12. Calin GA and Croce CM: MicroRNA signatures in human cancers. Nat Rev Cancer 6: 857-866, 2006.

13. Zhang B, Pan X, Cobb GP and Anderson TA: microRNAs as oncogenes and tumor suppressors. Dev Biol 302: 1-12, 2007.

14. Farazi TA, Hoell JI, Morozov P and Tuschl T: MicroRNAs in human cancer. Adv Exp Med Biol 774: 1-20, 2013.

15. Tang W, Wan S, Yang Z, Teschendorff AE and Zou Q: Tumor origin detection with tissue-specific miRNA and DNA methylation markers. Bioinformatics 34: 398-406, 2018.

16. Yamamoto Y, Yoshioka Y, Minoura K, Takahashi RU, Takeshita F, Taya T, Horii R, Fukuoka Y, Kato T, Kosaka N, et al: An integrative genomic analysis revealed the relevance of microRNA and gene expression for drug-resistance in human breast cancer cells. Mol Cancer 10: 135, 2011.

17. Yang Q, Jia C, Wang P, Xiong M, Cui J, Li L, Wang W, Wu Q, Chen Y and Zhang T: MicroRNA-505 identified from patients with essential hypertension impairs endothelial cell migration and tube formation. Int J Cardiol 177: 925-934, 2014.

18. Escate R,Mata P,Cepeda JM,PadróT and BadimonL: miR-505-3p controls chemokine receptor up-regulation in macrophages: Role in familial hypercholesterolemia. FASEB J 32: 601-612, 2018.
19. Liu YJ, Li W, Chang F, Liu JN, Lin JX and Chen DX: MicroRNA-505 is downregulated in human osteosarcoma and regulates cell proliferation, migration and invasion. Oncol Rep 39: 491-500, 2018.

20. Lu L, Qiu C, Li D, Bai G, Liang J and Yang Q: MicroRNA-505 suppresses proliferation and invasion in hepatoma cells by directly targeting high-mobility group box 1 . Life Sci 157: 12-18, 2016.

21. Ma C, Xu B, Husaiyin S, Wang L, Wusainahong K, Ma J, Zhu K and Niyazi M: MicroRNA-505 predicts prognosis and acts as tumor inhibitor in cervical carcinoma with inverse association with FZD4. Biomed Pharmacother 92: 586-594, 2017.

22. Chen S, Sun KX, Liu BL, Zong ZH and Zhao Y: MicroRNA-505 functions as a tumor suppressor in endometrial cancer by targeting TGF- $\alpha$. Mol Cancer 15: 11, 2016.

23. Paner GP, Stadler WM, Hansel DE, Montironi R, Lin DW and Amin MB: Updates in the Eighth Edition of the Tumor-NodeMetastasis Staging Classification for Urologic Cancers. Eur Urol 73: 560-569, 2018.

24. Livak KJ and Schmittgen TD: Analysis of relative gene expression data using real-time quantitative PCR and the $2\left({ }^{\Delta \Delta} \mathrm{C}(\mathrm{T})\right)$ method. Methods 25: 402-408, 2001.

25. Yang Z, Wang XL, Bai R, Liu WY, Li X, Liu M, Tang H: miR-23a promotes IKK $\alpha$ expression but suppresses ST7L expression to contribute to the malignancy of epithelial ovarian cancer cells. Br J Cancer 115: 731-740, 2016.

26. Samanta AK, Huang HJ, Le XF, Mao W, Lu KH, Bast RC Jr and Liao WS: MEKK 3 expression correlates with nuclear factor kappa B activity and with expression of antiapoptotic genes in serous ovarian carcinoma. Cancer 115: 3897-3908, 2009.

27. Landi MT, Zhao Y, Rotunno M, Koshiol J, Liu H, Bergen AW, Rubagotti M, Goldstein AM, Linnoila I, Marincola FM, et al: MicroRNA expression differentiates histology and predicts survival of lung cancer. Clin Cancer Res 16: 430-441, 2010.

28. Du X, Zhang J, Wang J, Lin X and Ding F: Role of miRNA in lung cancer-potential biomarkers and therapies. Curr Pharm Des 23: 5997-6010, 2018.

29. Yang CL, Zheng XL, Ye K, Ge H, Sun YN, Lu YF and Fan QX: MicroRNA-183 acts as a tumor suppressor in human non-small cell lung cancer by down-regulating MTA1. Cell Physiol Biochem 46: 93-106, 2018.

30. Qi Z, Zhang B, Zhang J, Hu Q, Xu F, Chen B and Zhu C: MicroRNA-30b inhibits non-small cell lung cancer cell growth by targeting the epidermal growth factor receptor. Neoplasma 65 : 192-200, 2018.

31. Huang RS, Zheng YL, Li C, Ding $\mathrm{C}, \mathrm{Xu} \mathrm{C}$ and Zhao J: MicroRNA-485-5p suppresses growth and metastasis in non-small cell lung cancer cells by targeting IGF2BP2. Life Sci 199: 104-111, 2018.

32. Wu D, Liu J, Chen J, He H, Ma H and Lv X: MiR-449a suppresses tumor growth, migration and invasion in non-small cell lung cancer by targeting HMGB1-mediated NF- $\kappa$ B signaling way. Oncol Res: Mar 21, 2018 (Epub ahead of print).

33. Liu M, Zhang Y, Zhang J, Cai H, Zhang C, Yang Z, Niu Y, Wang H, Wei X, Wang W, et al: MicroRNA-1253 suppresses cell proliferation and invasion of non-small-cell lung carcinoma by targeting WNT5A. Cell Death Dis 9: 189, 2018.

34. Liu J, Jia Y, Jia L, Li T, Yang L and Zhang G: MicroRNA-615-3p inhibits the tumor growth and metastasis of NSCLC via inhibiting IGF2. Oncol Res: Mar 21, 2018 (Epub ahead of print).

35. Ding X, Zhong T, Jiang L, Huang J, Xia Y and Hu R: miR-25 enhances cell migration and invasion in non-small-cell lung cancer cells via ERK signaling pathway by inhibiting KLF4. Mol Med Rep 17: 7005-7016, 2018.

36. Chang L and Karin M: Mammalian MAP kinase signalling cascades. Nature 410: 37-40, 2001.

37. Johnson GL and Lapadat R: Mitogen-activated protein kinase pathways mediated by ERK, JNK, and p38 protein kinases. Science 298: 1911-1912, 2002.

38. Yang J, Lin Y, Guo Z, Cheng J, Huang J, Deng L, Liao W, Chen Z, Liu Z and Su B: The essential role of MEKK3 in TNF-induced NF-kappaB activation. Nat Immunol 2: 620-624, 2001.

39. Hasan R, Sharma R, Saraya A, Chattopadhyay TK, DattaGupta S Walfish PG, Chauhan SS and Ralhan R: Mitogen activated protein kinase kinase kinase 3 (MAP3K3/MEKK3) overexpression is an early event in esophageal tumorigenesis and is a predictor of poor disease prognosis. BMC Cancer 14: 1-7, 2014. 
40. Fan Y, Ge N, Wang X, Sun W, Mao R, Bu W, Creighton CJ,Zheng P Vasudevan S, An L, et al: Amplification and over-expression of MAP3K3 gene in human breast cancer promotes formation and survival of breast cancer cells. J Pathol 232: 75-86, 2014.

41. Jia W, Dong Y, Tao L, Pang L, Ren Y, Liang W, Jiang J, Cheng G, Zhang WJ, Yuan X, et al: MAP3K3 overexpression is associated with poor survival in ovarian carcinoma. Hum Pathol 50: 162-169, 2016

42. He Y, Wang L, Liu W, Zhong J, Bai S, Wang Z, Thomas DG, Lin J, Reddy RM, Ramnath N, et al: MAP3K3 expression in tumor cells and tumor-infiltrating lymphocytes is correlated with favorable patient survival in lung cancer. Sci Rep 5: 11471, 2015.

43. Iqbal MA, Arora S, Prakasam G, Calin GA and Syed MA: MicroRNA in lung cancer: Role, mechanisms, pathways and therapeutic relevance. Mol Aspects Med 18: 30065-30067, 2018.
44. YaoL, Ye Y,MaoH,LuF,He X,Lu G andZhang S: MicroRNA-124 regulates the expression of MEKK3 in the inflammatory pathogenesis of Parkinson's disease. J Neuroinflammation 15: 13, 2018.

45. Zheng Y, Liu H and Kong Y: miR-188 promotes senescence of lineage-negative bone marrow cells by targeting MAP3K3 expression. FEBS Lett 591: 2290-2298, 2017.

46. Zhao L,Ni X,Zhao L, Zhang Y,Jin D, Yin W, Wang D and Zhang W: MiroRNA-188 acts as tumor suppressor in non-small-cell lung cancer by targeting MAP3K3. Mol Pharm 15: 1682-1689, 2018.

This work is licensed under a Creative Commons Attribution-NonCommercial-NoDerivatives 4.0 International (CC BY-NC-ND 4.0) License. 